\title{
LA OBJECIÓN DE CONCIENCIA FARMACÉUTICA. ANÁLISIS COMPARATIVO DE LOS MODELOS ESPAÑOL Y ESTADOUNIDENSE
}

ÓSCAR CELADOR ANGÓN 
SUMARIO

1. INTRODUCCIÓN. 2. OBJECIÓN DE CONCIENCIA. 2.1 Contenido y límites. 2.2 Naturaleza jurídica. 2.3 Objeción de conciencia farmacéutica. 2.3.1 Decisiones de los tribunales ordinarios. 2.3.2 Posición del Tribunal Constitucional. 3. POSICIÓN DEL TRIBUNAL EUROPEO DE DERECHOS HUMANOS. 4. LA OBJECIÓN DE CONCIENCIA EN EL ORDENAMIENTO JURÍDICO ESTADOUNIDENSE. 4.1 Marco constitucional. 4.2 La objeción de conciencia sanitaria. 4.3 La objeción de conciencia farmacéutica. 5. CONSIDERACIONES FINALES. 


\title{
LA OBJECIÓN DE CONCIENCIA FARMACÉUTICA. ANÁLISIS COMPARATIVO DE LOS MODELOS ESPAÑOL Y ESTADOUNIDENSE
}

\author{
ÓSCAR CELADOR ANGÓN \\ Universidad Carlos III de Madrid
}

\section{INTRODUCCIÓN}

La sociedad multicultural en la que, cada vez más, nos hallamos inmersos está poniendo en peligro algunas de las soluciones jurídicas tradicionales en el terreno de la libertad de conciencia. Este proceso se aprecia especialmente cuando se producen conflictos entre las creencias o convicciones personales y los mandatos contenidos en nuestro ordenamiento jurídico, que obligan a los individuos a elegir entre, bien seguir los dictados de su conciencia y afrontar las consecuencias inherentes al incumplimiento de la norma jurídica, o bien adecuar su comportamiento a lo dispuesto en el ordenamiento jurídico traicionando los dictados de su conciencia.

El libre desarrollo de la personalidad de acuerdo con un determinado sistema de creencias o convicciones es una manifestación del derecho a la libertad de conciencia, el cual, como viene señalando el Tribunal Constitucional, «no se agota en una dimensión interna del derecho a adoptar una determinada posición intelectual ante la vida y cuanto la concierne y a representar o enjuiciar la realidad según personales convicciones. Comprende además una dimensión externa de agere ligere con arreglo a las propias ideas sin sufrir por ello sanción o demérito, ni padecer la compulsión o la injerencia de los poderes públicos» ${ }^{1}$. La libertad

\footnotetext{
${ }^{1}$ STC $137 / 1990$ de 19 de julio de 1990, FJ. 8.
} 
de conciencia es una concreción de la libertad ideológica y religiosa que proclama el artículo 16.1 CE, mientras que la objeción de conciencia requiere la existencia de una norma imperativa que obligue al individuo a hacer o a no hacer algo en contra de lo que le ordenan sus creencias o convicciones personales, siendo en ese momento cuando el ordenamiento jurídico debe decidir qué bien debe primar: el que salvaguarda la norma o las creencias o convicciones personales $^{2}$.

En este contexto, parece lógico que la objeción de conciencia no pueda conformarse como un derecho fundamental o garantizarse con carácter general, ya que el reconocimiento del derecho a no cumplir lo dispuesto por el ordenamiento jurídico supondría la negación misma del Estado de derecho y la tiranía de la conciencia individual. Esta idea es compatible con la previsión de supuestos específicos en los cuales el ordenamiento jurídico reconozca la posibilidad de objetar en conciencia al cumplimiento de una norma (salvaguardando siempre el interés general y los derechos y libertades de terceros), permitiendo de esta manera que los individuos puedan actuar conforme a los dictados de su conciencia sin sufrir consecuencias jurídicas por ello ${ }^{3}$.

A partir de este planteamiento, el objeto de este estudio es analizar la objeción de conciencia farmacéutica tanto en nuestra reciente doctrina constitucional como en la jurisprudencia del Tribunal Supremo federal estadounidense y del Tribunal Europeo de Derechos Humanos (TEDH), para intentar explicar la coherencia (o incoherencia) de nuestro modelo de objeción de conciencia farmacéutica con el marco constitucional, así como en qué medida la posición de nuestro Tribunal Constitucional se asemeja a la de los tribunales referidos. El interés por conocer cuál es la solución ofrecida por el modelo estadounidense se debe a que este ordenamiento jurídico lleva décadas ofreciendo soluciones novedosas a este tipo de conflictos, y en el caso concreto de la objeción de conciencia farmacéutica el Tribunal Supremo federal acaba de pronunciarse sobre un supuesto planteado en términos muy similares al resuelto en la STC 145/2015, aunque utilizando una receta muy diferente a la nuestra para resolver el conflicto entre norma y conciencia.

2 Castro Jover, A. (1998). «La libertad de la conciencia y la objeción de la conciencia individual en la jurisprudencia constitucional española», La libertad religiosa y de conciencia ante la justicia constitucional, Granada, Comares, p. 147.

3 Capodiferro Cubero, D. (2015). La objeción de conciencia a la interrupción del embarazo, Madrid, CEPC, p. 12. 


\section{OBJECIÓN DE CONCIENCIA}

\subsection{Contenido y limites}

Una de las principales funciones del ordenamiento jurídico es conceder a los individuos el espacio necesario para que éstos puedan desarrollar libremente su personalidad, y para ello en numerosos supuestos es necesario imponer a sus destinatarios obligaciones o prohibiciones que pueden colisionar con sus sistemas de creencias o convicciones personales ${ }^{4}$. En este sentido, es indiferente que las creencias o convicciones sean religiosas o seculares, lo importante es la relevancia que esas creencias o convicciones tenga en el fuero interno del individuo, su sinceridad y en qué medida éstas obliguen a los individuos a actuar de una u otra manera ${ }^{5}$.

La objeción de conciencia ha sido definida como «una reacción individual ante una auténtica contradicción entre norma de conciencia y norma jurídica (de manera que una prohíbe lo que la otra tipifica como obligatorio), y no ante una mera discordancia por regular el Derecho imperativamente una conducta que la conciencia individual considera de libre decisión personal» ${ }^{6}$. Así pues, cabe hablar de objeción de conciencia en aquellos supuestos en los que una norma jurídica obliga a un individuo (se trata siempre de un conflicto individual de carácter personalisimo) a hacer algo que su conciencia considera prohibido, o bien cuando la norma jurídica no permite hacer algo que la conciencia ordena hacer; en ambos supuestos es necesario que el incumplimiento de la norma jurídica suponga la imposición de una sanción al individuo incumplidor ${ }^{7}$. La víctima del conflicto entre norma y conciencia a priori puede enfrentarse a tres escenarios diferentes: bien que el ordenamiento jurídico consciente del conflicto que genera a su sistema de creencias o convicciones le exima de la aplicación de la norma; bien que el ordenamiento jurídico prevea que el individuo afectado pueda sustituir el cumplimiento de la obligación jurídica por otra prestación (como ocurría con la objeción de conciencia al servicio militar); o bien no cumplir con

${ }^{4}$ STC 53/1985, de 11 de abril de 1985, FJ. 8.

5 Vid. Peces-Barba, G. (1984). Los valores superiores. Madrid, Tecnos, p. 49. Llamazares Fernández, D. (2003). Derecho de la Libertad de Conciencia (II), Libertad de Conciencia, identidad personal y solidaridad, Madrid, Cívitas, p. 285.

${ }^{6}$ Llamazares Fernández, D. (2010). Educación e Ideología, Colección Conciencia y Derecho, Madrid, Dykinson, p. 133.

7 Castro Jover, A. (1998). La libertad de la conciencia y la objeción de la conciencia, cit., p. 137. 
aquello que ordena o prohíbe el ordenamiento jurídico y aceptar las consecuencias jurídicas previstas en este sentido ${ }^{8}$.

Respecto a los límites de la libertad de conciencia, el artículo 16.1 CE señala que este derecho no tendrá «más limitación, en sus manifestaciones, que la necesaria para el mantenimiento del orden público protegido por la ley». El artículo 3.1 de la Ley Orgánica de Libertad Religiosa (LOLR) reconduce los elementos constitutivos del orden público a: la protección del derecho de los demás al ejercicio de sus libertades públicas y derechos fundamentales, y la salvaguardia de la seguridad, de la salud y de la moralidad pública ${ }^{9}$. De acuerdo con el artículo 10.2 CE, los tratados internacionales sobre derechos humanos ratificados por nuestro país también nos aportan pautas interpretativas en este terreno, destacando el artículo 9.2 del Convenio Europeo de Derechos Humanos $(\mathrm{CEDH})$, que señala que la libertad de conciencia puede ser limitada cuando así lo ordene la ley y se trate de «medidas necesarias, en una sociedad democrática, para la seguridad pública, la protección del orden, de la salud o de la moral públicas, o la protección de los derechos o las libertades de los demás» ${ }^{10}$.

La libertad de conciencia de los profesionales sanitarios está condicionada por dos límites adicionales a los señalados: por una parte, los derechos a la vida y a la salud de los pacientes; y por otra, lo que la doctrina ha denominado como la «voluntad legítima del paciente», cuando dicha voluntad no obligue a los profesionales sanitarios a realizar actuaciones u omisiones prohibidas por el ordenamiento jurídico ${ }^{11}$. El término salud al que se refieren la LOLR y el CEDH

${ }^{8}$ Vid. Contreras Mazarío, J. M. (2007). «La libertad de conciencia y convicción en el sistema constitucional español», Revista CIDOB d'afers internacionals, N. 77 , p. 52. DE MigUEL BERIAIN, I. (2010). «La objeción de conciencia del farmacéutico: Una mirada crítica», Revista de derecho UNED, N. ${ }^{\circ}$ 6, pp. 173-198. Martínez-Torrón, J. (2003). «Los límites a la libertad de religión y de creencia en el Convenio Europeo de Derechos Humanos», Revista General de Derecho Canónico y Derecho Eclesiástico del Estado, N. ${ }^{2}$. Martínez-Torrón, J. (1989). «Las objeciones de conciencia en el derecho internacional», Quaderni di Diritto e Politica ecclesiastica, N. ${ }^{\circ}$ 989/2, p. 171.

9 Castro Jover, A. (1998). La libertad de la conciencia y la objeción de la conciencia, cit., pp. 180-181.

10 Vid. Celador Angón, O. (2011). Libertad de conciencia y Europa: un estudio sobre las tradiciones constitucionales comunes y el CEDH, Madrid, Dykinson, p. 27 y ss. López GuZMÁN, J. (2006). «El farmacéutico comunitario y la objeción de conciencia», Aula de la farmacia: revista profesional de formación continuada, Vol. 3, N. 27, pp. 55-63. Ruiz Bursón, F. J. (2013). «Novedades desde Estrasburgo sobre la objeción de conciencia», Revista General de Derecho Canónico y Derecho Eclesiástico del Estado, N. 31 , pp. 1-27.

11 Como ha señalado De Miguel, «la autonomía del paciente prima sobre la conciencia del médico, de tal modo que si, por ejemplo, el paciente decide rechazar el tratamiento indicado para su dolencia, aun cuando ello le acaree la muerte, el médico no podrá en ningún caso imponérselo atendiendo a su derecho a la objeción de conciencia». De Miguel Beriain, I. (2010). La objeción 
también puede desempeñar cierto protagonismo en este terreno, especialmente si se atiende a la posición del Tribunal Constitucional que, en el caso de la negativa de los Testigos de Jehová a que les sean realizadas transfusiones de sangre, ha señalado que «el derecho a la libertad religiosa garantizado por el artículo 16.1 de la Constitución tiene como límite la salud de las personas» ${ }^{12}$. A priori, la interpretación del término salud en su dimensión individual, trasladada al terreno de la objeción de conciencia farmacéutica, supone un serio límite a la capacidad de actuar de los farmacéuticos, en la medida en la que su negativa por motivos de conciencia a dispensar determinados medicamentos ponga en peligro la salud o legítimos derechos de terceros ${ }^{13}$.

En resumen, si bien el Estado tiene que garantizar el derecho de los individuos a actuar de acuerdo con sus creencias o convicciones, este derecho puede ser objeto de numerosas limitaciones, y especialmente cuando se pone en peligro el ejercicio de las libertades públicas y derechos fundamentales de terceros.

\subsection{Naturaleza jurídica}

La objeción de conciencia ha sido reconocida en nuestro ordenamiento jurídico en dos supuestos. El artículo 30.2 CE establece la objeción de conciencia como una de las causas de exención del servicio militar obligatorio, y el artículo 19.2 de la Ley Orgánica 2/2010, de 3 de marzo, de salud sexual y reproductiva y de la interrupción voluntaria del embarazo, reconoce el derecho a la objeción de conciencia a los profesionales sanitarios directamente implicados en la interrupción voluntaria del embarazo (IVE). En ambos supuestos el reconocimiento del derecho a la objeción de conciencia se realiza de forma expresa, y se prevé tanto la situación jurídica del objetor como una serie de medidas que aseguren que el bien jurídico contra el que se objeta no se sacrifique, en un supuesto mediante la posibilidad de realizar una prestación social sustitutoria, y en el otro habilitando un modelo que salvaguarda los derechos de la mujer embarazada en el cual la administración asume directamente el coste de la IVE en un centro privado.

de conciencia del farmacéutico, cit., p. 186. En esta línea Vid. Capodiferro Cubero, D. (2013). La objeción de conciencia: estructura y pautas de ponderación, Barcelona, Bosch, p. 141.

${ }^{12}$ ATC 369/1984, de 20 de junio, FJ. 3. ${ }^{\circ}$

13 Sobre la salud pública o la protección de los derechos del ámbito sanitario como límites a la objeción de conciencia, en especial en el supuesto de la interrupción del embarazo, Vid. CAPODiferro Cubero, D. (2015). La objeción de conciencia, cit., p. 182 y ss. En esta misma obra se puede encontrar un desarrollo detallado de todos los problemas que surgen alrededor de este supuesto de objeción de conciencia. 
La doctrina se encuentra dividida respecto a la configuración jurídica de la objeción de conciencia, en torno a dos posiciones. Para unos, la objeción de conciencia se configura como un derecho fundamental que encuentra su fundamento en el derecho a la libertad ideológica y religiosa que garantiza el artículo 16.1 $\mathrm{CE}$, de forma que la objeción de conciencia supondría que los individuos tienen derecho a comportarse de acuerdo con sus creencias o convicciones en cualquier contexto, y sin que sea necesario que el legislador habilite el ejercicio del derecho mencionado; así entendida la objeción de conciencia, su alcance deberá determinarse atendiendo a los bienes jurídicos con los que su ejercicio pueda colisionar. Para otro sector de la doctrina, si bien la objeción de conciencia es una manifestación de la libertad ideológica y religiosa, que tiene por objeto el pleno ejercicio de los derechos los mencionados, no existe un derecho general a la objeción de conciencia, pues en otro caso se pondría en peligro el Estado de Derecho; asimismo, el ejercicio de la objeción de conciencia está limitado a aquellos supuestos en los que el legislador o excepcionalmente el Tribunal Constitucional así lo han previsto expresamente atendiendo a la naturaleza de los bienes jurídicos en juego ${ }^{14}$.

El Tribunal Constitucional ha tenido que pronunciarse en diferentes ocasiones sobre aspectos claves relacionados con la naturaleza jurídica de la objeción de conciencia, y en especial acerca de si el texto constitucional ampara un hipotético derecho general a la objeción de conciencia en el marco del derecho a la libertad ideológica y religiosa; o si por el contrario solo cabe hablar del derecho a la objeción de conciencia en aquellos supuestos en los que la Constitución o las leyes así lo han previsto expresamente ${ }^{15}$. Como a continuación veremos, la respuesta del tribunal a los interrogantes aludidos ha sido cambiante.

En un primer momento, el Tribunal Constitucional señaló que «puesto que la libertad de conciencia es una concreción de la libertad ideológica, que nuestra Constitución reconoce en el artículo 16, puede afirmarse que la objeción de conciencia es un derecho reconocido explícita e implícitamente en el ordenamiento constitucional español, sin que contra la argumentación expuesta tenga valor alguno el hecho de que el artículo 30.2 emplee la expresión «la Ley regulará», la cual no significa otra cosa que la necesidad de la interpositio legislatoris

14 Vid. La acertada síntesis del debate que realiza BARrero OrtegA, A. (2016). «La objeción de conciencia farmacéutica», Revista de estudios políticos, N. ${ }^{\circ} 172$, 2016, pp. 86-87.

15 Vid. Colmenero García, M. D. (2002), «La objeción de conciencia», Revista jurídica de la Región de Murcia, N. ${ }^{3}$ 32, p. 4. MARTín SÁNCHEZ, I. (2009). «Objeción de conciencia y educación para la ciudadanía», Revista jurídica Universidad Autónoma de Madrid, N. ${ }^{19}$, pp. 211-228. 
no para reconocer, sino, como las propias palabras indican, para «regular» el derecho en términos que permitan su plena aplicabilidad y eficacia» ${ }^{16}$.

El tribunal confirmó esta doctrina posteriormente ${ }^{17}$, y señaló en relación a la objeción de conciencia en el contexto de la IVE, si bien como obiter dictum pues el tema enjuiciado y decidido por el Tribunal Constitucional no versaba sobre la objeción de conciencia del personal sanitario, que: "por lo que se refiere al derecho a la objeción de conciencia, que existe y puede ser ejercido con independencia de que se haya dictado o no tal regulación. La objeción de conciencia forma parte del contenido del derecho fundamental a la libertad ideológica y religiosa reconocido en el artículo 16.1 de la Constitución y, como ha indicado este Tribunal en diversas ocasiones, la Constitución es directamente aplicable, especialmente en materia de derechos fundamentales» ${ }^{18}$.

El tribunal vinculó la objeción de conciencia y la libertad de conciencia, fundamentado ésta relación en la libertad ideológica y religiosa que garantiza el artículo $16 \mathrm{CE}$, de forma que, al menos en esta fase inicial, cabe hablar de un derecho general de objeción de conciencia que puede ser ejercido sin necesidad de desarrollo legislativo previo ${ }^{19}$.

Posteriormente, el Tribunal Constitucional adoptó una posición muy diferente al negar la categoría de derecho fundamental a la objeción de conciencia al servicio militar pues, en sus palabras, «se trata, ciertamente de un derecho que supone la concreción de la libertad ideológica reconocida en el artículo 16 de la Norma suprema. Pero de ello no puede deducirse que nos encontremos ante una pura y simple aplicación de dicha libertad. La objeción de conciencia con carácter general, es decir, el derecho a ser eximido del cumplimiento de los deberes constitucionales o legales por resultar ese cumplimiento contrario a las propias convicciones, no está reconocido ni cabe imaginar que lo estuviera en nuestro Derecho o en Derecho alguno, pues significaría la negación misma de la idea del Estado [...] se trata de un derecho constitucional reconocido por la Norma suprema en su artículo 30.2, protegido, sí, por el recurso de amparo (art. 53.2),

16 STC 15/1982, de 23 de abril de 1982, FJ. 6

17 Vid. STC 23/1982, de 13 de mayo; STC 25/1982, de 19 de mayo.

18 STC 53/1985, de 11 de abril de 1985, FJ. 14.

19 Vid. Martínez-Torrón, J. (2005). «Las objeciones de conciencia de los católicos», Revista General de Derecho Canónico y Derecho Eclesiástico del Estado, N. o 9, pp. 3 y ss. Rojo ÁlvarEZManzaneda, M. L. (2008), «La objeción de conciencia farmacéutica y la sentencia del Tribunal superior de justicia de Andalucía de 8 de enero de 2007», Revista General de Derecho Canónico y Derecho Eclesiástico del Estado, N. ${ }^{\circ}$ 16, pp. 1-12. GonZÁleZ-VAras IBÁÑEZ, A. (2007). «La objeción de conciencia del farmacéutico en la Jurisprudencia y su regulación legal en España», Revista General de Derecho Canónico y Derecho Eclesiástico del Estado, N. ${ }^{15}$, pp. 12 ss. 
pero cuya relación con el artículo 16 (libertad ideológica) ni autoriza ni permite calificarlo de fundamental» ${ }^{20}$.

A partir de ese momento, la doctrina constitucional se ha caracterizado por los siguientes parámetros: primero, el único supuesto garantizado por el texto constitucional a la objeción de conciencia es el referido al servicio militar (art. $30.2 \mathrm{CE}$ ), que se configura como un derecho constitucional autónomo de naturaleza excepcional ${ }^{21}$; segundo, las libertades ideológica y religiosa que garantiza el artículo 16 CE no amparan un hipotético derecho a la objeción de conciencia de carácter general, ya que, por una parte, la objeción de conciencia no forma parte del contenido esencial de las libertades ideológica y religiosa, y por otra, lo contrario haría peligrar las bases del Estado de derecho; tercero, de forma excepcional, y atendiendo a la naturaleza de los bienes jurídicos en juego, la objeción de conciencia de los médicos a participar en la IVE forma parte del contenido de las libertades ideológica y religiosa, pero su ejercicio puede ser limitado para salvaguardar otros bienes jurídicos ${ }^{22}$; y cuarto, el legislador puede reconocer la posibilidad de no cumplir determinados mandamientos jurídicos por motivos de conciencia, y en ese supuesto estaríamos ante un derecho de configuración legal, como ha ocurrido, por ejemplo, con la IVE (art. 19.2 LO $2 / 2010)^{23}$. La doctrina constitucional referida se ha mantenido estable hasta la STC $145 / 2015$.

En esta línea, el Tribunal Supremo ha señalado, respecto a la objeción de conciencia a participar en mesas electorales, que: «la objeción de conciencia de carácter constitucional está limitada en nuestro Derecho al no cumplimiento del servicio militar y no puede equipararse nunca a ella la pretendida de formar parte de una mesa electoral» ${ }^{24}$. Por su parte, el Tribunal Constitucional ha expuesto en sendos autos declarando la inadmisión de recursos de amparo, relacionados con las objeciones de conciencia de una funcionaria de prisiones a suministrar metadona a un recluso y el de un contribuyente a pagar impuestos, que: «la objeción de conciencia, en cuanto derecho constituido por una excepción a un concreto deber constitucional (el del art. $30 \mathrm{CE}$ ) no puede ser extendida subjetivamente, por razón de las propias creencias, más allá del ámbito objetivo del deber general que la Constitución establece» ${ }^{25}$; así como que: «la Constitu-

20 STC 160/1987, de 27 de octubre, FJ. 3. STC 161/1987, de 27 de octubre, FJ. 5.

21 STC 161/1987, de 27 de octubre, FJ. 2.

22 Barrero Ortega, A. (2016). La objeción de conciencia farmacéutica, cit., pp. 94-95.

23 Colmenero García. M. D. (2002), La objeción de conciencia, cit., p. 45.

24 Castro Jover, A. (1998). La libertad de la conciencia y la objeción de la conciencia, cit., p. 16. LlamaZares Fernández, D. (2003). Derecho de la Libertad, cit., p. 290.

25 ATC 71/1993 de 1 de marzo, FJ. 3. 
ción (o la legislación) no ha reconocido un derecho genérico a la objeción de conciencia aplicable a los deberes constitucionales y legales - excepto el art. 30.2 CE - que se imponen a los ciudadanos en general y muy especialmente a quien, cual la recurrente, se halla inmersa en una organización jerárquica como la Administración Pública que determina un régimen especial de derechos y obligaciones ${ }^{26}$.

\subsection{La Objeción de conciencia farmacéutica}

El artículo 43 CE reconoce el derecho a la protección de la salud y encomienda a los poderes públicos organizar y tutelar un modelo de salud pública a través de medidas preventivas y de las prestaciones y servicios necesarios. El tribunal Constitucional ha vinculado el derecho a la salud con el derecho a la vida y a la integridad física y moral que garantiza el artículo $15 \mathrm{CE}$, ya que es «evidente que los intereses generales y públicos, vinculados a la promoción y garantía del derecho a la salud, son intereses asociados a la defensa de bienes constitucionales particularmente sensibles» ${ }^{27}$. En este contexto, las farmacias se configuran como establecimientos sanitarios privados de interés público ${ }^{28}$, sujetos a planificación

${ }^{26}$ ATC 135/2000 de 8 de junio, FJ. 2. Como ha señalado Alenda, «La doctrina sobre objeción de conciencia en general contenida en las Sentencias del Tribunal Constitucional núms. 160 y 161, ambas de 27 de octubre de 1987, puede considerarse definitiva a tenor de los pronunciamientos posteriores del propio Tribunal, como la Providencia de 28 de junio de 1990 y el Auto 71/1993, de 1 de marzo (ambos en materia de objeción «fiscal») y la Sentencia 321/1994, de 28 de noviembre (objeción a la prestación social sustitutoria del servicio militar)». AlENDA SALINAS, M. (2008). «La píldora del día después: su conflictividad jurídica como manifestación de la objeción de conciencia farmacéutica», Revista General de Derecho Canónico y Derecho Eclesiástico del Estado, N. ' 16, p. 7.

27 Vid. ATC 239/2012, de FJ 5, 8. STC 126/2008, de 27 de octubre, FJ6. Sobre este particular, Vid. Beltrán Aguirre, J. L. (2015). «La contención del gasto farmacéutico público versus el acceso de los ciudadanos a los medicamentos», Revista Aranzadi Doctrinal, N. ${ }^{\circ}$ 5, pp. 151-163. Fernández Montalvo, R. (2010). «Dimensión del derecho a la protección a la salud: su tratamiento en la jurisprudencia del Tribunal Constitucional», Derecho y salud, Vol. 19, pp. 11-30. Solanes Corella, A. (2014). «La salud como derecho en España: reformas en un contexto de crisis económica», Derechos y libertades: Revista del Instituto Bartolomé de las Casas, Año n. ${ }^{\circ} 18$, N. $^{\circ} 31$, pp. 127-162.

28 Vid. artículos 103.2 de la Ley 14/1986, de 25 de abril, general de sanidad, y 84.6 de la Ley 29/2006, de 26 de julio, de garantías y uso racional de los medicamentos y productos sanitarios. 
sanitaria de acuerdo con las disposiciones de las Administraciones sanitarias, que están «obligados a dispensar los medicamentos que se les demanden tanto por los particulares como por el Sistema Nacional de Salud en las condiciones reglamentarias establecidas ${ }^{29}$.

La Ley 29/2006, de 26 de julio, de garantías y uso racional de los medicamentos y productos sanitarios, establece que las farmacias tienen la obligación de dispensar los medicamentos que les sean requeridos, y especialmente aquellos que se soliciten con receta médica (arts. 2 y 84.3). Por lo tanto, las farmacias, por una parte, deben disponer de las exigencias mínimas materiales que establezca el Gobierno con carácter básico para asegurar la prestación de una correcta asistencia sanitaria, sin perjuicio de las competencias que tengan atribuidas las Comunidades Autónomas en esta materia (art. 84. 2. c); y por otra, en el supuesto de que el farmacéutico no dispusiera de un medicamento que le sea demandado, éste deberá ofrecer un medicamento sustitutivo si lo permite la ley, y en todo caso solicitar los suministros necesarios para atender la demanda $(\operatorname{art} .86)^{30}$.

La negativa a dispensar medicamentos sin causa justificada, así como cualquier acto u omisión encaminados a coartar la libertad del usuario en la elección de la oficina de farmacia, se configuran como infracciones graves ${ }^{31}$. La causa justificada se refiere a la negativa del farmacéutico a despachar un medicamento que requiere receta cuando el paciente carece de la misma, ya que la receta se

29 Vid. artículo 84 de la Ley 29/2006, de 26 de julio, de garantías y uso racional de los medicamentos y productos sanitarios. Artículo 3.1 del RD 1/2015, de 24 de julio, por el que se aprueba el texto refundido de la Ley de garantías y uso racional de los medicamentos y productos sanitarios. STC 83/2014 de 29 de mayo, FJ. 3

30 Como ha señalado De Miguel, el mandato se refiere: «a todos los medicamentos reconocidos como tales y no solo a aquellos que se venden bajo prescripción médica. En consecuencia, no cabe suponer que un farmacéutico pueda abstenerse de cumplir el deber jurídico de disponer de ellos sobre esta base. La obligatoriedad de la prescripción médica y de la disposición de un medicamento no son sinónimos, sino que la segunda obligación es mucho más amplia que la primera» De Miguel Beriain, I. (2010). La objeción de conciencia del farmacéutico, cit., p. 188.

31 Vid. artículo 101 b) 15 y 26 de la Ley 29/2006, de 26 de julio, de garantías y uso racional de los medicamentos y productos sanitarios, redactado según el apartado cuarenta y ocho del artículo único de la Ley 10/2013, de 24 de julio, por la que se incorporan al ordenamiento jurídico español las Directivas 2010/84/UE del Parlamento Europeo y del Consejo, de 15 de diciembre de 2010, sobre fármaco vigilancia, y 2011/62/UE del Parlamento Europeo y del Consejo, de 8 de junio de 2011, sobre prevención de la entrada de medicamentos falsificados en la cadena de suministro legal, y se modifica la Ley 29/2006, de 26 de julio, de garantías y uso racional de los medicamentos y productos sanitario. 
configura como una garantía de presentación del servicio farmacéutico al paciente ${ }^{32}$.

A partir de este planteamiento, cabe hablar de objeción de conciencia en el terreno farmacéutico cuando se produce un conflicto entre el sistema de creencias y convicciones individuales de los profesionales farmacéuticos y sus obligaciones profesionales y/o contractuales (normalmente al negarse a dispensar o almacenar un medicamento). En otras palabras, la objeción de conciencia es una decisión individual de carácter personal que pueden plantear los farmacéuticos en función de sus concretas creencias o convicciones, pero en ningún caso cabe adjudicar o predicar dicha objeción de conciencia de la farmacia. Como telón de fondo de este debate se encuentra la obligación de Estado de garantizar el derecho de los usuarios de los servicios sanitarios a recibir la prestación o el tratamiento médico debidos.

La legislación de algunas Comunidades Autónomas ha reconocido la posibilidad de que los farmacéuticos objeten en conciencia. Por ejemplo, el artículo 3.2 de la Ley 7/2001, de 19 de diciembre, de Ordenación Farmacéutica de Cantabria establece que: «La Administración sanitaria garantizará que el derecho a la objeción de conciencia del profesional farmacéutico no limite o condicione los derechos de los ciudadanos recogidos en el apartado anterior, adoptando las medidas oportunas».

Esta regulación genera diversos interrogantes, como, por ejemplo, ¿tienen competencias las Comunidades Autónomas para regular la objeción de conciencia? Según González Saquero, se trata de un claro vicio de inconstitucionalidad por vulnerar el reparto constitucional de competencias, ya que se estaría eximiendo al farmacéutico de la responsabilidad y las sanciones que prevé la Ley 29/2006, que está aprobada en virtud de un doble título competencial previsto en el artículo $149.1 .16 .^{\circ} \mathrm{CE}$, referido tanto a las bases y coordinación general de la sanidad como a la legislación sobre productos farmacéuticos ${ }^{33}$. Desde esta perspectiva, una vez que la legislación nacional ha decidido no reconocer la objeción de conciencia y sancionar la negativa de los farmacéuticos a dispensar medicamentos, dada la naturaleza del servicio público que prestan las farmacias, las Comunidades Autónomas podrían aumentar la sanción prevista en la legislación estatal, que actuaría a modo de mínimo, pero en ningún caso diseñar un régimen que contradiga lo previsto por el legislador nacional.

32 González Saquero, P. (2008). «¿Derecho a la objeción de conciencia del farmacéutico? A propósito de la decisión sobre admisibilidad del Tribunal Europeo de Derechos Humanos, as. Pichon y Sajous c. Francia, de 2 de octubre de 2001», Foro, Nueva época, N. 8 , 2008, pp. $258,265$.

33 González Saquero, P. (2008). ¿Derecho a la objeción de conciencia, cit., p. 268. 
Los estatutos y códigos deontológicos aprobados por algunos colegios profesionales también han reconocido el derecho de los farmacéuticos a la objeción de conciencia. Por ejemplo, el artículo 6 del Código deontológico del Colegio Oficial de Farmacéuticos de Madrid señala que: «El ejercicio profesional del farmacéutico, le faculta para que en la práctica de su actividad pueda ejercer su derecho a la objeción de conciencia. El farmacéutico al que se condicionase o impidiese el ejercicio de este derecho, recibirá de la organización colegial el asesoramiento legal y, en su caso la ayuda necesaria para la defensa del mismo» ${ }^{34}$.

La relevancia jurídica de este tipo de disposiciones en la materia que nos ocupa es nula por diversos motivos. En primer lugar, de acuerdo con la Ley sobre Colegios Profesionales, una de las finalidades de los colegios es «la la protección de los intereses de los consumidores y usuarios de los servicios de sus colegiados» ${ }^{35}$, y en este contexto parece que no tiene cabida proclamar un teórico derecho a la objeción de conciencia que por definición supone mermar los intereses de los consumidores y usuarios. En segundo lugar, en el caso de tener eficacia jurídica el reconocimiento a la objeción de conciencia proclamado por los códigos deontológicos, nos encontraríamos con una disposición que contradeciría la legislación imperativa aprobada en este terreno, y en consecuencia ante un acto nulo de pleno derecho que carecería ab initio de efectos jurídicos. Y en tercer lugar, las previsiones de los códigos deontológicos y los estatutos de los colegios profesionales deben desarrollarse de conformidad con la Constitución, las leyes y el resto del ordenamiento jurídico, y el reconocimiento del derecho a la objeción de conciencia es una competencia que le corresponde en exclusiva al legislador constitucional o nacional, que en todo caso debe respetar los derechos constitucionales (art. $43 \mathrm{CE}$ ) y las legítimas expectativas de terceros ${ }^{36}$.

${ }^{34}$ El texto completo del Código deontológico puede consultarse en http://www.cofm.es/es/ ventanilla-unica/codigo-deontologico/ (29/09/2016).

35 Vid. Art. 3 de la Ley 2/1974, de 13 de febrero, sobre Colegios Profesionales, redactado por el número uno del artículo 5 de la Ley 25/2009, de 22 de diciembre, de modificación de diversas leyes para su adaptación a la Ley sobre el libre acceso a las actividades de servicios y su ejercicio. Corresponde a los Colegios Profesionales el ejercicio de las siguientes funciones, en su ámbito territorial. El artículo 5 a) señala que «Corresponde a los Colegios Profesionales el ejercicio de las siguientes funciones, en su ámbito territorial: a) Cuantas funciones redunden en beneficio de la protección de los intereses de los consumidores y usuarios de los servicios de sus colegiados».

36 Vid. El voto particular del Magistrado Valdés Dal-Ré a la STC 145/2015, de 25 de junio de 2015 . 


\subsubsection{Decisiones de los tribunales ordinarios}

La píldora del día después (PDD) se comercializa en nuestro país desde el 2001, y desde 2009 puede adquirirse en farmacias sin receta ${ }^{37}$. En el 2001 la Junta de Andalucía ordenó la inclusión de los progestágenos y los preservativos en la regulación de existencias mínimas de medicamentos y productos sanitarios que deben estar disponibles en las oficinas de farmacia y almacenes farmacéuticos. La legislación andaluza prohibió tácitamente la objeción de conciencia en este contexto, al establecer como infracción grave la negativa a la dispensación en los términos legalmente establecidos de medicamentos y productos sanitarios incluidos en las listas oficiales de existencias mínimas, y como infracción muy grave la reincidencia en la comisión de infracciones graves ${ }^{38}$. En este contexto, hay que tener en cuenta que la dispensación: «es un acto terapéutico exclusivamente farmacéutico que, para verificarse, requiere de un farmacéutico legamente autorizado y ser realizada en una oficina de farmacia o servicio farmacéutico» ${ }^{39}$.

Ante estos hechos, un farmacéutico interpuso dos recursos, uno por la vía de la protección de los derechos fundamentales, resuelto por el Tribunal Superior de Justicia (TSJ) de Andalucía en Sentencia de 30 de julio de 2002, y confirmado posteriormente en recurso de casación por la sala de lo contencioso administrativo del Tribunal Supremo; y un segundo recurso ante la jurisdicción de lo contencioso administrativo, resuelto por la sentencia del TSJ de Andalucía de 8 de enero de $2007^{40}$. En ambos supuestos el recurrente alegó que la disposición mencionada vulneraba tanto el derecho fundamental a la vida, como su derecho a la libertad de conciencia.

La sala de lo contencioso administrativo del Tribunal Supremo confirmó la sentencia del TSJ andaluz, desestimando y dejando imprejuzgado el recurso por falta de legitimación de la parte actora, señalando a este respecto que: «en el caso de la objeción de conciencia, su contenido constitucional forma parte de la libertad ideológica reconocida en el artículo 16.1 de la CE (STC 53/85), en estrecha relación con la dignidad de la persona humana, el libre desarrollo de la personalidad (art. 10 CE) y el derecho a la integridad física y moral (art. 15 CE), lo que no excluye la reserva de una acción en garantía de este derecho para aquellos

37 Vid. Díez Fernández, J. A. (2015). «La constitucionalidad de la objeción de conciencia farmacéutica», Revista General de Derecho Canónico y Derecho Eclesiástico del Estado, N. . 39, p. 4.

38 Vid. Arts. 75.1.d) y 76.1.e) de la Ley 22/2007, de 18 de diciembre, de Farmacia de Andalucía.

39 López Guzmán, J. (1997). Objeción de conciencia farmacéutica, Barcelona, Ediciones Internacionales Universitarias, p.116.

40 Sentencias 628/2002 de 30 de julio y $1 / 2007$ de 8 de enero. 
profesionales sanitarios con competencias en materia de prescripción y dispensación de medicamentos, circunstancia no concurrente en este caso» ${ }^{41}$. De nuevo estamos ante un obiter dictum, que en cuanto tal no entra al fondo del problema, y que parece extender la posibilidad de objetar en conciencia a los farmacéuticos ${ }^{42}$.

En enero del 2007 el TSJ andaluz se pronunció de nuevo sobre este asunto, desestimando el recurso y declarando conforme a derecho la norma autonómica impugnada. En palabras del tribunal, «el objetor de conciencia, no puede hacer prevalecer o imponer a otros sus condiciones religiosas o morales, para justificar la nulidad de una norma general [...] dicha objeción de conciencia, puede ser enarbolada cuando, en virtud de la no aplicación de dicha norma, puedan derivarse perjuicios o sanciones por su incumplimiento. Pero que solo produciría efectos excepcionales y puntuales, personales e individuales en aquellos que la esgriman frente al incumplimiento de la obligación, como autoriza el artículo 28 del Código de Ética Farmacéutica, al señalar «que la responsabilidad y libertad personal del farmacéutico le faculta para ejercer su derecho de objeción de conciencia respetando la libertad y el derecho a la vida y la salud del paciente» y el artículo 33 del mismo Código Ético compromete a la Organización Colegial a la defensa de quienes hayan decidido declararse objetores, como derecho individual al cumplimiento de una obligación impuesta por la norma impugnada, pero que no autoriza su impugnación por declaración de nulidad con carácter general para todos los farmacéuticos que no ejerciten el derecho a objetar» ${ }^{43}$.

El TSJ andaluz estableció que las creencias o convicciones individuales no pueden prevalecer frente a una norma de carácter general, por lo que no estimó el recurso. Sin embargo, el tribunal parece ver en un concreto código deontológico una fuente de derechos, que habilitaría al colectivo farmacéutico a negarse a cumplir con lo dispuesto en una norma que salvaguarda un interés público de especial relevancia.

41 STS de 23 de abril de 2005, sala de lo contencioso-administrativo FJ.5.

${ }^{42}$ Las decisiones mencionadas del TSJ andaluz y del Tribunal Supremo han sido criticadas por un sector de la doctrina, al entender que se trata de opiniones extemporáneas que deforman el debate al descontextualizarlo. Vid. González SAquero, P. (2008). ¿Derecho a la objeción de conciencia, cit., p. 255. Llamazares Fernández, D. (2010). Educación e Ideología, Colección Conciencia y Derecho, Madrid, Dykinson, p. 139.

43 Sentencia 1/2008 de 4 de marzo, FJ. 5. Vid. González-VAras Ibáñez, A. (2007). La objeción de conciencia del farmacéutico, cit., p. 253. 


\subsubsection{Posición del Tribunal Constitucional}

El Tribunal Constitucional se ha pronunciado acerca de la objeción de conciencia farmacéutica ${ }^{44}$, ya que, después del largo proceso judicial descrito ante el TSJ andaluz y el Tribunal Supremo, el farmacéutico recurrió en amparo alegando que había sido sancionado por la administración por ejercer su derecho a la libertad de conciencia en el contexto profesional, y pese a que los medicamentos objeto de debate podían adquirirse en numerosas farmacias cercanas a la suya. También solicitó que se reconociera su derecho a la objeción de conciencia, en virtud de lo establecido en el artículo 8.5 de los estatutos del Colegio de Farmacéuticos de Sevilla y los artículos 28 y 33 del Código de ética y deontología de la profesión farmacéutica.

La decisión del Tribunal Constitucional ha basculado sobre la respuesta a dos interrogantes: en qué medida el derecho a la objeción de conciencia que la doctrina constitucional reconoce a los médicos en el contexto de la práctica de la IVE es extensible a los farmacéuticos, y cómo debe armonizarse esta posibilidad con los derechos de terceros y, en especial, con el derecho de la mujer a la salud y a acceder a la $\mathrm{PDD}^{45}$.

La decisión del tribunal se soportó principalmente en tres argumentos:

En primer lugar, el derecho de la mujer a la salud sexual y reproductiva significa que este colectivo debe poder acceder a determinadas prestaciones sanitarias y farmacéuticas, entre las que se encuentran la IVE en los supuestos legalmente previstos y los medicamentos anticonceptivos autorizados en nuestro país. La actuación del farmacéutico no puso en peligro el derecho mencionado, pues éste fue sancionado por incumplir la normativa sobre existencias mínimas de medicamentos, sin que fuera documentada ninguna denuncia o supuesto de denegación de medicamento. De forma complementaria, el tribunal dedujo que, dado que la farmacia estaba localizada en un centro urbano, la PDD estaría disponible en otras farmacias cercanas ${ }^{46}$.

En segundo lugar, el tribunal valoró el hecho de que el farmacéutico se acogiese al derecho a la objeción de conciencia que propone el Código de ética y deontología de la profesión farmacéutica; así como que estuviera inscrito como

44 STC 145/2015, de 25 de junio de 2015.

45 Como ha señalado Barrero, la sentencia es el resultado de dos posiciones enfrentadas, la de aquellos que ven en artículo $16 \mathrm{CE}$ un derecho general a la objeción de conciencia, y la de quienes entienden que solo existe la objeción de conciencia en aquellos supuestos en los que el legislador así lo señala expresamente. BArrero Ortega, A. (2016). La objeción de conciencia farmacéutica, cit., p. 96.

46 FJ. 5.

(C) UNED. Revista de Derecho Politico 
objetor de acuerdo con las disposiciones del Colegio de Farmacéuticos de Sevilla, cuyos estatutos habían sido aprobados por Orden de 30 de diciembre de 2005, de la Consejería de Justicia y Administración Pública de la Junta de Andalucía, previa calificación de su legalidad.

Y en tercer lugar, el tribunal estimó que la doctrina de la STC 53/1985 era aplicable al caso que nos ocupa, pues los motivos que subyacen en el conflicto entre norma y conciencia son similares en los supuestos de la negativa de los farmacéuticos a dispensar la PDD y en el de los profesionales sanitarios a participar en la $\operatorname{IVE}^{47}$.

A partir de estos argumentos, el tribunal llegó a la conclusión de que la sanción impuesta al farmacéutico por carecer de existencia mínimas de la PDD lesionó su derecho a la objeción de conciencia, vinculado al derecho fundamental a la libertad ideológica (art. 16.1 CE). Sin embargo, respecto a la carencia de exigencias mínimas de preservativos, el tribunal señaló que: «es patente que el incumplimiento de la obligación relativa a las existencias de preservativos queda extramuros de la protección que brinda el precepto constitucional indicado. La renuencia del demandante a disponer de profilácticos en su oficina de farmacia no queda amparada por la dimensión constitucional de la objeción de conciencia que dimana de la libertad de creencias reconocida en el artículo 16.1 CE. Ningún conflicto de conciencia con relevancia constitucional puede darse en este supuesto» ${ }^{48}$.

La sentencia fue objeto de tres votos particulares, a los que a continuación pasamos a referirnos.

La magistrada Asua criticó que el voto mayoritario fundamentase su decisión en la afirmación contenida en el obiter dictum de la STC 53/1985 anteriormente referido, ignorando de forma incomprensible la doctrina constitucional que viene estableciendo que: «la libertad ideológica o de conciencia (art. 16 CE) no es suficiente para liberar a los ciudadanos de deberes constitucionales o "subconstitucionales" por motivos de conciencia, con el riesgo anejo de relativizar los mandatos jurídicos» ${ }^{49}$. Asimismo, en opinión de la magistrada, el voto mayoritario reconoció un supuesto de objeción de conciencia que anula los derechos fundamentales a la integridad física y psíquica y a la salud de la mujer acreedora de la PDD, sin argumentar jurídicamente la equiparación entre la objeción
47 FJ. 4.
${ }^{48}$ FJ. 5.
${ }^{49}$ Punto 1 del voto particular. 
de conciencia farmacéutica y a la IVE, y presumiendo que al tratarse de un área céntrica habría más farmacias que evitarían que las mujeres fueran desatendidas ${ }^{50}$.

El Magistrado Valdés Dal-Ré también firmó un voto contrario a la sentencia, al que se adhirió el Magistrado Xiol Ríos. La farmacia fue sancionada por carecer de existencias de la PDD y de preservativos, y no porque uno de sus titulares se negase a dispensar dichos productos. De hecho la sanción se dirige a la farmacia sin diferenciar entre sus dos cotitulares, y «la objeción de conciencia pretendida no puede extenderse sobre el establecimiento farmacéutico, en su conjunto, como si se tratara de una unidad personal. Así lo pide la propia configuración de la libertad ideológica y de la objeción de conciencia como derechos personales e intransferibles» ${ }^{51}$. Desde esta perspectiva, al no haberse lesionado un derecho constitucional no hay posibilidad de reparación y, como recuerda el magistrado, no existe derecho al amparo cautelar.

Por último, el magistrado Ollero emitió un voto particular suscribiendo el amparo, pero discordante respecto a la obligación de los farmacéuticos de dispensar preservativos, pues: «al no tratarse de un medicamento sino de un producto higiénico, suele hallarse disponible en máquinas tragaperras instaladas en lugares públicos, sin obligada intervención de farmacéutico alguno» ${ }^{52}$. Por este motivo, en opinión del magistrado, sancionar por no dispensar este producto a quien se ha reconocido el derecho a objetar en conciencia a dispensar la PDD carece de sentido.

Como hemos visto, la posición del Tribunal Constitucional en el terreno de la objeción de conciencia farmacéutica es compleja, tanto por los argumentos utilizados por el tribunal como por las consecuencias que esta decisión está llamada a tener en la conformación de la futura doctrina constitucional en la materia, dado que parece habilitar la posibilidad de que los individuos puedan oponerse al cumplimiento de las leyes alegando motivos de conciencia sin que sea necesaria la interpositio legislatoris.

Los argumentos sobre los que se soporta la decisión del tribunal son muy frágiles. La equiparación entre los supuestos de objeción de conciencia frente a la IVE y a la dispensación de la PDD presenta diversas dificultades, entre las que destaca el diferente papel que desempeñan el médico y el farmacéutico, pues el primero participa de forma directa en la IVE, mientras que el farmacéutico participa indirectamente y la PDD no tiene la configuración de un medicamento abortivo. En un intento por explicar la lógica interna de la decisión judicial,

50 Punto 6 del voto particular.

51 Punto 3 del voto particular.

52 Punto 4 del voto particular. 
Barrero ha señalado que: «la base conflictual que late en la objeción del médico a participar en la IVE y en la objeción de conciencia del farmacéutico a expender la píldora poscoital se anuda a una misma finalidad, preservar la concepción del objetor sobre la vida. A ello se añade la existencia de una «duda razonable» sobre el efecto abortivo de la píldora y que la actuación del farmacéutico, en su condición de expendedor autorizado, es particularmente relevante. Hay un paralelismo que aconseja la ampliación de la STC 53/1985» ${ }^{53}$. Ahora bien, el voto mayoritario no aclara en qué medida esta posición es coherente con la doctrina del tribunal que señala que la vida comienza una vez que el óvulo fecundado se implanta en el útero y adquiere el status de embrión ${ }^{54}$.

La decisión del tribunal parece ignorar que el derecho estatutario debe desarrollarse de acuerdo con la Constitución, las leyes que se dicten en la materia y el resto del ordenamiento jurídico, ya que concede una relevancia jurídica muy discutible a los estatutos del Colegio de Farmacéuticos de Sevilla y al Código de ética y deontología de la profesión farmacéutica; pese a que contradicen la propia finalidad de la corporación (al sacrificar los intereses de los consumidores de los servicios de sus colegiados ${ }^{55}$ ), y las legislaciones sanitaria andaluza y nacional ${ }^{56}$. Asimismo, sin aportar ningún dato objetivo, se presume que la objeción de conciencia del farmacéutico no lesiona derechos de terceros porque su farmacia está localizada en una zona céntrica de una gran ciudad, por lo que la PDD debería poder obtenerse en establecimientos cercanos; y tampoco queda claro cómo se determina la relación entre farmacias y población necesaria para poder hablar de objeción de conciencia sin perturbar la correcta prestación de servicio público, y especialmente en las zonas rurales.

53 «El TC, en suma, admite que la propia indefinición de la cuestión de fondo, el comienzo de la vida humana, debería llevarnos a ser más comprensivos con los reparos morales que el farmacéutico pueda sentir frente a la dispensación de la PDD, otorgándole, al menos, la misma consideración que a los médicos. En realizad, una categoría como la objeción de conciencia está, precisamente, pensada para casos como estos, en los que no existen respuestas generales, sino que el disenso es perfectamente comprensible y, por lo tanto, puede ser legitimado por el ordenamiento jurídico. Un voto de confianza a causa de una duda razonable». BArrero OrtegA, A. (2016). La objeción de conciencia farmacéutica, cit., pp. 95 y 97.

54 Tal y como señala en su voto particular la Magistrada Asua, en relación a la STC 116/1999, de 17 de junio. Vid. STC 83/2014 de 29 de mayo, FJ. 6. Sánchez-Tarazaga Marcelino, J. (2015). «Algunas reflexiones acerca de la Sentencia del Tribunal Constitucional de 25 de junio de 2015 sobre la objeción de conciencia y la PDD», Revista General de Derecho Canónico y Derecho Eclesiástico del Estado, n. ${ }^{\circ}$ 39, pp. 5-6.

55 Vid. Art. 5 de la Ley 25/2009, de 22 de diciembre, de modificación de diversas leyes para su adaptación a la Ley sobre el libre acceso a las actividades de servicios y su ejercicio.

56 Especialmente revelador a este respecto es el último párrafo del voto particular firmado por el Magistrado Valdés Dal-Ré al que se adhirió el Magistrado don Xiol Ríos. 
El voto mayoritario concede un tratamiento diferente a la objeción de conciencia del farmacéutico según se trate de almacenar y dispensar la PDD o preservativos, sin explicar adecuadamente el motivo de tal diferenciación y sin atender al hecho de que la PDD se configura como un medicamento y los preservativos como un producto sanitario ${ }^{57}$. La exclusión de los preservativos del análisis constitucional ha sido muy criticada por la doctrina ${ }^{58}$, y solo puede explicarse si se tiene en cuenta que, por una parte, el voto mayoritario ha interpretado que la objeción de conciencia de los farmacéuticos es equiparable a la de los médicos en el caso de la IVE; y por la otra que, dado que el preservativo carece de efectos abortivos y el legislador no ha previsto de forma expresa la objeción de conciencia a su dispensación, no existe un conflicto de derechos que sea necesario ponderar ${ }^{59}$.

Por último, la decisión del tribunal tampoco parece coherente desde la perspectiva del principio de laicidad, que, según la doctrina constitucional, «veda cualquier tipo de confusión entre fines religiosos y estatales» ${ }^{60}$, e impide que los valores e intereses religiosos se erijan en parámetros para medir la legitimidad o justicia de las normas y actos de los poderes públicos» ${ }^{61}$. Las farmacias se configuran como establecimientos sanitarios privados de interés público, debido al papel que desempeñan para el pleno ejercicio de los derechos a la salud y a la

57 López GuZmán, J. (1997). Objeción de conciencia farmacéutica, cit., p. 83, 93-97. VIDA Fernández, J. (2015). Concepto y Régimen Jurídico de los Medicamentos, Madrid, Tirant lo Blanch, p. 113, 117 y ss. Vid. MARTínez-Torrón, J. (2015). «La objeción de conciencia farmacéutica en la reciente jurisprudencia constitucional española: otra oportunidad perdida», Revista General de Derecho Canónico y Derecho Eclesiástico del Estado, N. ${ }^{\circ}$ 39, pp. 13 -14.

58 Como ha señalado MARTínEZ-Torrón, «el principal error de bulto que comete aquí la sentencia consiste en negar la dimensión constitucional del problema, lo cual implica afirmar que unas convicciones de conciencia son merecedoras de la protección del artículo 16 CE y otras no, sin que se explique por qué ni cuál sería el criterio para distinguir unas de otras. No es fácil compatibilizar un tal planteamiento con la neutralidad religiosa y ética del Estado». MARTíNEZTorrón, J. (2015). La objeción de conciencia farmacéutica, cit., p. 26. En palabras de Gómez Abeja, «Lo que no se entiende, a la vista de la lógica seguida por el Tribunal, es que en la propia sentencia se descarte la posibilidad para el farmacéutico de ejercer la objeción de conciencia también al deber de disposición y dispensación de preservativos [...] aplicando el razonamiento del propio Tribunal, insisto, no se entiende que la STC 145/2015 niegue toda relevancia constitucional a este otro conflicto de conciencia, como ha sido puesto de manifiesto en dos votos particulares, uno discrepante y otro concurrente, por lo demás absolutamente opuestos». GómEZ ABEJA, L. (2016). «El tribunal constitucional ante el conflicto de conciencia del farmacéutico: una solución de compromiso a gusto de nadie», Revista de derecho constitucional europeo, N. ${ }^{\circ}$ 25, 2016, p. 14.

59 Barrero Ortega, A. (2016). La objeción de conciencia farmacéutica, cit., p. 96.

60 Vid. STC 177/1996 de 11 de noviembre de 1996, STC 46/2001de 15 de febrero de 2001.

${ }^{61}$ STC 24/1982, de 13 de mayo, FJ.1; STC 46/2001de 15 de febrero de 2001 FJ. 4. 
integridad física y psíquica, lo que justifica que su actividad esté condicionada por las directrices que a tales efectos señale la Administración competente ${ }^{62}$. La posibilidad de que un farmacéutico pueda objetar en conciencia a dispensar medicamentos implica que los sujetos que acceden a este servicio público puedan ser discriminados, atendiendo a cuáles sean las creencias o convicciones de los farmacéuticos, y que por lo tanto la prestación del servicio público no sea ideológica y/o religiosamente neutral.

\section{POSICIÓN DEL TRIBUNAL EUROPEO DE DERECHOS HUMANOS}

El artículo 9.1 del CEDH reconoce el derecho a la libertad de pensamiento, conciencia y de religión, al que define como: «la libertad de cambiar de religión o de convicciones, así como la libertad de manifestar la religión o las convicciones individual o colectivamente, en público o en privado, por medio del culto, la enseñanza, las prácticas y la observancia de los ritos». El artículo 9.2 señala que la libertad para manifestar la religión o las convicciones puede ser objeto de limitación cuando así lo prevea la ley y sean: «medidas necesarias, en una sociedad democrática, para la seguridad pública, la protección del orden, de la salud o de la moral públicas, o la protección de los derechos o las libertades de los demás». De la lectura del artículo 9, no se desprende que la objeción de conciencia forme parte de la libertad de pensamiento, conciencia y de religión, toda vez que las manifestaciones de las creencias o convicciones personales pueden ser limitadas por los poderes públicos en los supuestos referidos.

El TEDH se ha mostrado reacio a reconocer un hipotético derecho a la objeción de conciencia en la línea del artículo 10.2 de la Carta de los Derechos Fundamentales de la Unión Europea, que reconoce el derecho a la objeción de conciencia exclusivamente «de acuerdo con las leyes nacionales que regulen su ejercicio». La decisión de la Comisión Europea de Derechos Humanos en el asunto Heudens v. Belgium es ilustrativa a este respecto, pues ha señalado que: «La Comisión recuerda que ni el Convenio ni sus Protocolos garantizan, como tal, el derecho a la objeción de conciencia y que el artículo 9 del Convenio, que

62 Como ha señalado Gomez Abeja «El deber de disposición y dispensación del farmacéutico es una de las prestaciones en que se materializa el derecho a la protección de la salud del artículo 43.1 CE. Otro derecho igualmente involucrado en este contexto es el que la usuaria de la farmacia tiene a obtener el medicamento solicitado, manifestación de otro a decidir sobre el propio tratamiento, que forma parte a su vez del derecho a la integridad física del artículo 15 CE». GómEz ABEJA, L. (2016). El tribunal constitucional ante el conflicto, cit., p. 20. 
garantiza el derecho a la libertad de pensamiento, de conciencia y de religión, no reconoce a los objetores de conciencia el derecho a la exención del servicio militar o civil sustitutorio» ${ }^{63}$.

En la sentencia que resolvió el asunto Bayatyan v Armenia ${ }^{64}$ el TEDH se pronunció sobre el papel de la objeción de conciencia en el marco del CEDH. Un Testigo de Jehová se negó a realizar el servicio militar por razones de conciencia cuando fue reclutado en 2001, y solicitó realizar un servicio social sustitutorio. En aquel momento Armenia no disponía de una ley que regulase el servicio social sustitutorio, por lo que, ante la reiterada negativa del objetor a realizar el servicio militar, éste fue condenado a una pena privativa de libertad. El señor Bayatyan denunció que la condena que le fue impuesta vulneraba su derecho a la libertad de conciencia garantizado en el artículo 9 del CEDH, y alegó en su defensa que el 25 de enero de 2001, cuando Armenia se incorporó al Consejo de Europa, este país se comprometió a crear un servicio social sustitutorio al servicio militar en el plazo de tres años, así como a perdonar a todos los objetores de conciencia condenados a penas privativas de libertad.

Respecto a la relación entre el artículo 9 del CEDH y la objeción de conciencia, el tribunal recordó que la Comisión había optado por excluir los supuestos de objeción de conciencia al servicio militar del artículo 9, y reconducirlos al artículo 4.3 (b) del Convenio, según el cual: no tiene la consideración de «trabajo forzado u obligatorio» en el sentido del presente artículo: [...] b) todo servicio de carácter militar o, en el caso de objetores de conciencia en los países en que la objeción de conciencia sea reconocida como legítima, cualquier otro servicio sustitutivo del servicio militar obligatorio» ${ }^{65}$. Ahora bien, según el tribunal, la objeción de conciencia al servicio militar presenta una especificad única respecto a los demás supuestos de objeción, dado que existe un elevado grado de consenso entre los países firmantes del CEDH. Cuando el señor Bayatyan se negó a realizar el servicio militar por motivos de conciencia solamente 4 países, además de Armenia, no reconocían en sus ordenamientos jurídicos el derecho a la objeción de conciencia al servicio militar, y en el momento en que se enjuició el asunto solamente Turquía y Azerbaiyán no reconocían dicho derecho. De hecho, nada más presentar la demanda ante el TEDH el señor Bayatyan, Armenia modificó su ordenamiento jurídico incorporando el derecho a la obje-

${ }^{63}$ Heudens v. Belgium, 24630/94, decidido el 22 de mayo de 1995. El texto completo de la decisión está disponible en http://hudoc.echr.coe.int/eng?i=001-2246 (29/09/2016).

64 Bayatyan v Armenia, recurso application no. 23459/03, decidido el 7 July de 2011. El texto completo de la sentencia está disponible en http://hudoc.echr.coe.int/eng?i=001-105611 (29/09/2016).

65 Vid. \& 99.

(C) UNED. Revista de Derecho Politico 
ción de conciencia al servicio militar; por lo que a Armenia solo le quedaba cumplir con el compromiso de perdonar a los objetores que estaban en prisión ${ }^{66}$.

Finalmente, el tribunal estimó que hubo una violación del artículo 9 del Convenio. Armenia no fue condenada porque su ordenamiento jurídico no reconociera el derecho a la objeción de conciencia al servicio militar, sino porque el itinerario legislativo y el cumplimiento de los compromisos adquiridos por este país en este terreno fueron erráticos.

En el caso concreto de la objeción de conciencia en el contexto sanitario, la Asamblea Parlamentaria del Consejo de Europa ha emitido una serie de recomendaciones que, si bien carecen de carácter vinculante, defienden la necesidad de armonizar el derecho de los pacientes a recibir los tratamientos médicos que les sean prescritos y el derecho de objeción de conciencia del personal sanitario, pero en cualquier caso los Estados están obligados a «garantizar que los pacientes reciban el tratamiento adecuado, y especialmente en los supuestos de emergencia» ${ }^{67}$.

A este planteamiento obedece la decisión del TEDH en el asunto Pichon y Sajous v. Francia ${ }^{68}$, donde el tribunal se pronunció sobre la negativa de dos farmacéuticos franceses a dispensar contraceptivos a tres mujeres por motivos de conciencia, pese a que éstos habían sido prescritos por un facultativo autorizado a tales efectos. Los farmacéuticos fueron declarados culpables por los tribunales franceses que enjuiciaron el asunto, al entender que los farmacéuticos no pueden amparase en sus creencias o convicciones para negarse a dispensar un medicamento, especialmente cuando la venta de medicamentos está reservada en exclusiva a este colectivo.

Los farmacéuticos recurrieron ante el TEDH, alegando que la negativa de los tribunales franceses a reconocer su derecho a la objeción de conciencia constituyó una vulneración de su derecho a la libertad de conciencia garantizado en el artículo 9 del CEDH. El tribunal inadmitió el recurso al entender, por una parte, que la objeción de conciencia no está protegida por la libertad de pensa-

66 Vid. \& 104, 115.

${ }^{67}$ Vid. punto 4. 3 de la Resolución 1763 de 2010. El texto de la resolución puede encontrarse en http://assembly.coe.int/nw/xml/News/FeaturesManager-View-EN.asp? ID = 950 (29/09/2016). Esta posición ha sido posteriormente ratificada en el punto 9.10 de la Resolución 1928 (2013) sobre «Protección de los derechos humanos en relación con la religión y las creencias y la protección de las comunidades religiosas de la violencia». El texto puede encontrarse en https://assembly.coe.int/nw/xml/XRef/Xref-XML2HTML-en.asp? fileid = 19695\&lang =en (29/09/2016).

68 Pichon and Sajous v France, decisión de inadminisbilidad de la reclamación n 49853/99, de 2 de octubre de 2001. El texto completo de la sentencia está disponible en http://hudoc.echr. coe.int/eng? $\mathrm{i}=001-43011(29 / 09 / 2016)$. 
miento, conciencia y religión, que garantiza el artículo 9 del CEDH; por otra, que el ordenamiento jurídico francés no prevé ni expresa ni tácitamente que los farmacéuticos puedan alegar motivos de conciencia para no dispensar medicamentos; y por último, la legislación francesa permite la venta de medicamentos contraceptivos y las farmacias disfrutan del monopolio de dispensación de los mismos.

En palabras del tribunal, el artículo 9 del CEDH protege tanto las convicciones personales y las creencias religiosas, como los actos estrechamente relacionados con las mismas en contextos como el culto, la enseñanza o la práctica religiosa, pero «no garantiza en todos los supuestos el derecho a comportarse en público de acuerdo con las convicciones o creencias personales. La palabra «práctica» que se utiliza en el artículo 9.1 no se refiere a todos y cada uno de los actos o comportamientos motivados o inspirados por una religión o una creencia». Esto no quiere decir que los farmacéuticos no tengan derecho a expresar o manifestar sus creencias o convicciones, sino «que han de ejercer ese derecho fuera de su esfera profesional, y en todo caso sin lesionar los derechos de terceros que pretenden acceder a un medicamento lícitamente prescrito por un profesional de la salud» ${ }^{69}$.

La decisión del TEDH en el asunto Pichon ha sido interpretada de forma dispar por la doctrina. Por ejemplo, Martínez-Torrón ha expuesto que la decisión del tribunal: «más que argumentar, adopta como premisa un concepto restringido de libertad religiosa y de conciencia [...] restringir la tutela de la libertad religiosa a los actos de culto o devoción no solo es una inaceptable interpretación restrictiva del artículo $9 \mathrm{CEDH}$, constituye además una invasión del Estado en el ámbito de la conciencia, al arrogarse la potestad de dictaminar qué conductas son realmente importantes para la identidad religiosa y moral de una persona. La consecuencia de esa interpretación, entre otras, es la pérdida de operatividad jurídica de una parte esencial del derecho garantizado por el artículo $9 \mathrm{CEDH}$ : el derecho a comportarse de acuerdo con las propias convicciones» ${ }^{70}$. Mientras que otros autores han utilizado al asunto Pichon para señalar que, salvo la excep-

69 El tribunal soportó su decisión en los asuntos: Kalaç v. Turquia, de 1 de julio de 1997, y Cha'are Shalom Ve Tsedek v. Francia de 27 de junio del 2000.

70 Martínez-Torrón, J. (2015). «La objeción de conciencia farmacéutica, cit., pp. 10, 11. En la misma línea Vid. Díez Fernández, J. A. (2015). «La constitucionalidad de la objeción de conciencia farmacéutica», Revista General de Derecho Canónico y Derecho Eclesiástico del Estado, Vol. 39, p. 10. SÁnCheZ-TARAZAGa Y Marcelino, J. (2015). «Algunas reflexiones acerca de la sentencia del Tribunal Constitucional de 25 de junio de 2015 sobre la objeción de conciencia y la PDD», Revista General de Derecho Canónico y Derecho Eclesiástico del Estado, Vol. 39, p. 15.

(C) UNED. Revista de Derecho Politico 
ción referida de la objeción de conciencia al servicio militar, de la jurisprudencia del TEDH no cabe deducir que la objeción de conciencia forme parte de la libertad de creencias que garantiza el artículo 9 del $\mathrm{CEDH}^{71}$.

\section{LA OBJECIÓN DE CONCIENCIA EN EL ORDENAMIENTO JURÍDICO ESTADOUNIDENSE}

\subsection{Marco constitucional}

La primera enmienda a la Constitución federal estadounidense contiene dos mandatos que condicionan el modelo de relaciones entre el Estado y las confesiones religiosas. La primera cláusula prohíbe al Estado que pueda establecer a una Iglesia como oficial o primar a una religión sobre las demás. La segunda cláusula (free exercise clause) también contiene una prohibición para el Estado, en este caso referida a la imposibilidad de que sus normas impidan que los ciudadanos puedan ejercer su derecho a la libertad religiosa, o que lesionen las libertades de expresión, prensa y reunión ${ }^{72}$.

La libertad de conciencia se configura en el ordenamiento jurídico estadounidense como un derecho fundamental que deben garantizar los poderes públicos, pero su ejercicio puede ser limitado cuando éste entre en conflicto con la establishment clause. Como ha señalado el Tribunal Supremo federal, «la libertad

71 González Saquero, P. (2008). «¿Derecho a la objeción de conciencia, cit., p. 281. Barrero Ortega, A. (2016). «La objeción de conciencia farmacéutica», Revista de estudios políticos, N. ${ }^{\circ} 172,2016$, pp. 83-105.

72 Vid. Celador Angón, O. (1998). El estatuto jurídico de las confesiones religiosas en Estados Unidos, Madrid, Dykinson. DAVIS, D. (1996). «Resolving not to Resolve the Tension between the Establishment and the Free Exercise Clauses», Journal of Church and State, Vol. 38, pp. 247 y ss Esbeck, C., (1985). «Toward a General Theory of Church-State Relations and the First Amendment», Public Law Forum, Vol. 4, pp. 325-354. Bradlet, G. (1986). «Dogmatomachy - A "Privatization" Theory of the Religion Clause Cases», Saint Louis University Law Journal, Vol. 19, pp. 275-286. Goldford, D. J., (2012). The Constitution of Religious Freedom: God, Politics, and the First Amendment, Waco, Texas Baylor University Press. KutorofF, A, (2015). «First Amendment versus Laicite: Religious Exemptions, Religious Freedom, and Public Neutrality», Cornell international law journal, Vol. 48, N. 1, pp. 247-278. MCCOnNELl, M. W, BerG, T. C., Lund, C. C., (2016) Religion and the Constitution, 4th ed., New York, Wolters Kluwer. SmiTH, S. (1989). «Separation and the "Secular": Reconstructing the Disestablishment Decision», Texas Law Review, Vol. 67, pp. 955-970. Murray, B. T., (2008). Religious liberty in America: the first amendment in historical and contemporary perspective, Amherst, Massachusetts, University of Massachusetts Press. TUPI, B. S., (2007). «Religious freedom and the First Amendment», Duquesne law review, Vol. 45, N.2, pp. 195-262. 
que protegen la primera y la decimocuarta enmiendas es la libertad para creer y la libertad para actuar, la primera es absoluta, pero la libertad para practicar el propio credo es relativa, y admite límites ${ }^{73}$. De acuerdo con esta jurisprudencia, las normas estatales no pueden interferir en las creencias o convicciones pues pertenecen a la esfera interna de los individuos, pero pueden limitar sus manifestaciones externas cuando éstas atenten contra la salud, la seguridad ciudadana, el orden público o el bienestar de la sociedad ${ }^{74}$.

El Tribunal Supremo ha señalado que la establishment clause debe interpretarse en clave de neutralidad y separación entre el Estado y las confesiones religiosas. La neutralidad ideológica significa que el Estado no puede discriminar entre sus ciudadanos por tener unas u otras creencias o convicciones, o por carecer de las mismas; la neutralidad se configura como un requisito indispensable para que los ciudadanos puedan ejercer su libertad de pensamiento, conciencia y religión, en régimen de igualdad. La separación entre el Estado y las confesiones religiosas implica que ambas partes deben ser autónomas e independientes, de forma que puedan actuar libremente y sin injerencias en sus respectivos ámbitos competenciales $^{75}$.

Los conflictos entre las normas estatales imperativas y la libertad de conciencia han sido resueltos por el Tribunal Supremo desde la sentencia que resolvió el asunto Reynolds v. United States ${ }^{76}$, atendiendo a las especificidades que presenta cada caso concreto. De forma complementaria, el Tribunal Supremo creó en el asunto Sherbert la teoría del balancing test para determinar en qué supuestos las normas estatales que colisionan con las creencias o convicciones personales son inconstitucionales. El balancing test se compone de tres fases. Primero, la norma estatal debe obstaculizar o generar una lesión efectiva al ejercicio de la libertad de

73 Cantwell v. Connecticut, 310 U. S. 303-4 (1940). Acerca de la distinción que ha hecho el Tribunal Supremo entre actos y creencias protegidos por la primera enmienda Vid. CLARCK, E. (1969). «Guidelines for the Free Exercise Clause», Harvard Law Review, Vol. 83, pp. 327-365.

${ }^{74}$ Vid. Wisconsin v. Yoder, 406 U. S. 205, 215, 248-249 (1972). Sobre la objeción de conciencia en el ordenamiento jurídico estadounidense Vid. Martínez-Torrón, J., NaVArroVALls, R. (2011). Conflictos entre conciencia y ley. Las objeciones de conciencia, Madrid, Iustel. PALOmino Lozano, R. (1994) Las objeciones de Conciencia, Madrid, Montecorvo. Palomino Lozano, R. (2001). Las Objeciones de Conciencia en el Derecho Norteamericano, Madrid, Servicio de Publicaciones de la Universidad Complutense.

75 El Tribunal Supremo estableció en la sentencia que resolvió el caso Lemon v. Kurtzman que las normas estatales deben cumplir tres requisitos para no ser invalidadas a tenor de la cláusula de no establecimiento: su fin debe ser secular, su principal efecto no debe ser inhibir o fomentar a la religión y no deben generar una relación excesiva entre el Estado y la religión. 403 U. S. 602 (1971).

7698 U. S. 145 (1879).

(C) UNED. Revista de Derecho Politico 
conciencia, para lo que es necesario valorar la sinceridad y la relevancia de la práctica religiosa y en qué medida (el grado de interferencia) la norma estatal impide o limita el ejercicio del derecho fundamental ${ }^{77}$. Segundo, aplicando la teoría del compelling state interest, el tribunal debe determinar cuándo el interés del Estado (que tendrá la carga de la prueba) en que su norma sea efectiva es tan importante como para prevalecer sobre la libertad de conciencia en ese caso concreto. Y tercero, es necesario que el Estado no disponga de soluciones alternativas para ejecutar sus normas que obstaculizar el ejercicio de la libertad de conciencia, en cuyo caso deberá utilizar los medios menos restrictivos o lesivos ${ }^{78}$.

De esta manera, «Sherbert abrió la posibilidad de exenciones a leyes primo efecto neutrales, si gravan la libertad religiosa del individuo» ${ }^{79}$, y en este contexto, los tribunales deben valorar la relevancia del interés público que protege la norma, la forma prevista para su ejecución, y el perjuicio que sufriría el bien jurídico protegido por la norma en el supuesto de que se eximiese a los sujetos de su cumplimiento por motivos ideológicos o religiosos ${ }^{80}$.

El legislador estadounidense intentó delimitar el alcance y contenido del derecho a la libertad religiosa en 1993, mediante el Religious Freedom Restoration Act (RFRA) ${ }^{81}$. El Gobierno federal promulgó el RFRA como consecuencia de la decisión del Tribunal Supremo en el asunto Employment Division v. Smith ${ }^{82}$ para restaurar la doctrina del compelling state interest, y que los conflictos entre la libertad de conciencia y la legislación estatal fueran resueltos de acuerdo con los principios establecidos en el asunto Sherbert ${ }^{83}$.

En el asunto Smith, el tribunal estableció que no era necesario que en todos los supuestos en los que se produjese un conflicto entre una norma estatal de carácter neutral y el ejercicio de la libertad religiosa, el Estado demostrase que el

77 Vid. Sherbert v. Verner, 374 U. S. 398 (1963). Wisconsin v. Yoder, 406 U. S. 205 (1972).

78 Esta doctrina se incorporó al balancing test en la sentencia que resolvió el caso Braunfeld v. Brown, 366 U. S. 599 (1961); siendo posteriormente ratificada en la sentencia Sherbert v. Verner, 374 U. S. 398 (1963). Vid. Fried, C. (1963). Two Concepts of interest: Some reflections on the Supreme Court's Balancing test, Harvard Law Review, Vol. 76, pp. 755-758.

79 Palomino Lozano, R., (2007). Nuevos supuestos y formas de objeción de conciencia, cit., p. 2.

${ }^{80}$ Giannella, D. (1967). «Religious Liberty, Non establishment and Doctrinal Development: Part I. The Religious Liberty Guarantee», Harvard Law Review, Vol. 80, pp. 1381, 1390. Lupu, I. (1989). «Were the Rights Begin: The Problem of Burdems on the Free Exercise of Religion», Harvard Law Review, Vol. 102, pp. 933-990.

81 El Senado ratificó el Religious Freedom Restoration Act el 27 de Octubre de 1993 con 93 votos a favor y tres en contra.

82494 U. S. 872 (1990).

83 Sherbert v. Verner, 374 U. S. 398 (1963), y posteriormente ratificados en el asunto Wisconsin v. Yoder, 406 U. S. 205 (1972). 
fin de sus normas era lo suficientemente relevante como para limitar el ejercicio de la libertad religiosa. Con esta decisión, el Tribunal Supremo modificó su propia jurisprudencia establecida en el asunto Sherbert, y señaló que las leyes neutrales ${ }^{84}$ y de aplicación general (en este caso la norma del Estado de Oregón que prohibía y sancionaba el consumo de peyote) no son inconstitucionales pese a que puedan tener consecuencias indirectas en el ejercicio del derecho de libertad religiosa, como ocurrió con los miembros de la Iglesia Nativa Americana que consumen peyote con fines estrictamente espirituales durante sus rituales religiosos.

El Tribunal Supremo se manifestó acerca de la constitucionalidad del RFRA en la sentencia City of Boerne v. Flores, Archbishop of San Antonio ${ }^{85}$, con ocasión de un recurso presentado contra la legislación urbanística del municipio de Boerne, estimando que la aplicación del RFRA a la legislación de los Estados era inconstitucional, ya que el alcance del RFRA suponía una extralimitación de las competencias legislativas del Gobierno federal. Esta situación ha provocado que numerosos Estados hayan promulgado su propia legislación para regular el alcance y contenido del derecho de libertad religiosa ${ }^{86}$. Respecto a la aplicación del RFRA a la legislación federal, el Tribunal Supremo federal estimó la constitucionalidad de la misma en la sentencia que resolvió el asunto Gonzales v. O Centro Espirita Beneficente Uniao do Vegetal en el $2006^{87}$.

\subsection{La objeción de conciencia sanitaria}

La Constitución federal estadounidense no contiene ninguna referencia a la salud, y las Constituciones de los Estados como regla general no conciben el acceso al sistema sanitario como un derecho o garantizan el derecho a la salud, por lo que la gestión del modelo sanitario se realiza principalmente mediante un complejo sistema de seguros médicos de gestión y titularidad principalmente privada $^{88}$.

${ }^{84}$ En el sentido de que la principal finalidad de la norma objeto de debate no sea interferir en el ejercicio del derecho de libertad religiosa.

85521 U. S. 507 (1997).

${ }^{86}$ IsaAcson, S. E., (2016). «Derechos Establecidos y Nuevos Desafíos que Enfrenta la Objeción de Conciencia en los Estados Unidos», Revista General de Derecho Canónico y Derecho Eclesiástico del Estado, N. ${ }^{\circ} 42$, p. 12.

87546 U. S. 418 (2006).

88 Las bases jurídicas del actual modelo sanitario estadounidense se encuentran en el Patient Protection and Affordable Care Act (2010), y el Health Care and Education Affordability Reconciliation Act (2010). 
El alcance y contenido de la objeción de conciencia en el contexto sanitario en el ordenamiento jurídico estadounidense ha estado supeditado en gran medida a la atipicidad de su modelo sanitario, especialmente si se le compara con la realidad europea donde los modelos sanitarios están fuertemente vinculados al Estado social ${ }^{89}$. La alternancia política de republicanos y demócratas también ha desempeñado un papel importante en este terreno. La IVE fue declarada legal por el Tribunal Supremo en la decisión que resolvió el asunto Roe contra Wade $^{90}$, donde el tribunal estableció que la IVE es una manifestación del derecho al respeto a la vida privada que protege la decimocuarta enmienda a la Constitución federal. El legislador federal intentó proteger el derecho a la libertad de conciencia de los profesionales sanitarios mediante una enmienda a la Ley de salud Pública de 1973, que reconoció la objeción de conciencia del personal de los centros médicos financiados con fondos públicos; pero fue una norma de difícil aplicación, pues, como ha señalado Isaacson «no se creó ninguna acción

89 Existe una abundante bibliografía sobre esta temática, destacando los siguientes estudios: Davidson, L. A., (2010). «Religion and conscientious objection: A survey of pharmacists' willingness to dispense medications», Social science $\mathcal{E}$ medicine, 2010, Vol. 71, N. 1, pp. 161-165. Gedicks, F. M., VAn Tassell, R. G., (2014). «RFRA Exemptions from the Contraception Mandate: An Unconstitutional Accommodation of Religion», Harvard Civil Rights-Civil Liberties Law Review, Vol. 49, pp. 343-384. Gedicks, F. M., (2015). «One Cheer for Hobby Lobby: Improbably Alternatives, Trutly Strict Scrutiny, and Third-Party Employee Burdens», Harvard Journal of Law E Gender, Vol. 38, pp. 153-176. Gedicks, F. M., (2006). «The Permissible Scope of Legal Limitations on the Freedom of Religion or Belief in the United States», Emory International Law Journal, Vol. 16. pp1187-1275. IsAACson, S. E., (2016). «Derechos Establecidos y Nuevos Desafíos que Enfrenta la Objeción de Conciencia en los Estados Unidos», Revista General de Derecho Canónico y Derecho Eclesiástico del Estado, N. ${ }^{\circ} 42$. KelleHer, J. P., (2010). «Emergency Contraception and Conscientious Objection, Journal of applied philosophy», Vol. 27, N., 3, pp. 290-304. McConnell, M. W, «Reflections on Hosanna-Tabor», Harvard Journal of Law E Public Policy, Vol. 35, p. 821. (2012). Palomino Lozano, R., (2007). «Nuevos supuestos y formas de objeción de conciencia en los Estados Unidos de Norteamérica», Revista General de Derecho Canónico y Derecho Eclesiástico del Estado, N. ${ }^{\circ}$ 15. Posse-Blanco Lindberg, D. "¿Protección jurídica del derecho a la objeción de conciencia? El caso Stormans v. Wiesman», Revista General de Derecho Canónico y Derecho Eclesiástico del Estado, N. ${ }^{\circ}$ 42, 2016. WICCLAIR, M. (2006), «Pharmacies, Pharmacists, and Conscientious Objection», Kennedy Institute of Ethics Journal; Baltimore16.3, Sep 2006, pp. 225-250.

90410 U. S. 113,15 (1973). Esta sentencia, al igual que ha ocurrido recientemente con la sentencia que resolvió el asunto Obergefell v. Hodges (576 U. S. __, 2015) donde el Tribunal Supremo federal reconoció el derecho al matrimonio a las parejas del mismo sexo, fue muy polémica debido a que fue el órgano encargado de interpretar el texto constitucional y no el legislador (federal y/o estatal) el que lideró el proceso Vid. CELAdor Angón, O. (2015). «La secularización del matrimonio y el reconocimiento del derecho al matrimonio a las parejas del mismo sexo", Laicidad y Libertades: Escritos Jurídicos. N. 15, Vol. 2, pp. 496-503. 
para que los perjudicados pudieran hacer valer sus derechos» ${ }^{91}$. En esta línea, en diciembre de 2008, durante la administración Bush, se aprobó la denominada Right of Conscience Rule, que permitía a los trabajadores del sistema sanitario objetar por motivos de conciencia a participar en la prestación de determinados servicios médicos, siempre que no se pusiera en peligro la salud o la vida de los pacientes. La última palabra a este respecto la tenían los centros médicos, pero en el caso de que optasen por no reconocer a sus empleados el derecho a la objeción de conciencia no podrían solicitar o beneficiarse de ayudas o subvenciones federales $^{92}$. Esta disposición fue parcialmente anulada por la administración Obama en $2011^{93}$.

Los Estados han regulado la objeción de conciencia del personal sanitario de forma dispar; por ejemplo, mientras que la mayoría de los Estados reconocen de forma expresa el derecho a la objeción de conciencia de los médicos a participar en la IVE, otros Estados, como ocurre en el caso de California y Washington, no reconocen el derecho mencionado a los profesionales sanitarios y prohíben a los farmacéuticos negarse a proveer a sus clientes de determinados anticonceptivos o abortivos ${ }^{94}$.

El marco jurídico descrito ha propiciado que el Tribunal Supremo federal haya adquirido un elevado protagonismo en este terreno, destacando en este sentido dos decisiones recientes sobre el papel de los Estados en la regulación de la IVE, y la objeción de conciencia de los empleadores a pagar seguros médicos a sus empleados que incluyan medidas anticonceptivas o contraceptivas. A continuación pasamos a referirnos a ambas decisiones judiciales.

La competencia para regular en qué plazos y condiciones debe realizarse la IVE corresponde a los Estados miembros. La decisión del Tribunal Supremo de mayo del 2016, con ocasión del asunto Whole Woman's Health v. Hellerstedt ${ }^{95}$, ilustra cuál es la capacidad de los Estados en este contexto. En 2013 el Estado de Texas aprobó una norma ordenando a las clínicas que practicasen

91 IsaAcson, S. E., (2016). Derechos Establecidos y Nuevos Desafíos, cit., p. 7.

92 Vid. 42 U. S. Code $\$ 300 a-7$ (—Sterilization or abortions-).

93 El texto completo de la Regulation for the Enforcement of Federal Health Care Provider Conscience Protection Laws puede encontrarse en https://www.federalregister.gov/articles/2011/02/23/2011-3993/regulation-for-the-enforcement-of-federal-health-care-providerconscience-protection-laws (29/09/2016).

94 IsaAcson, S. E., (2016). «Derechos Establecidos y Nuevos Desafíos, cit., pp. 8-9. Sobre los diferentes modelos que la doctrina ha propuesto para evitar la colisión entre la norma y la libertad de conciencia de los farmacéuticos Vid. Palomino Lozano, R., (2007). Nuevos supuestos y formas de objeción de conciencia, cit., pp.11-15.

95579 U. S. _ (2016) El texto completo de la decisión se encuentra en: https://www. supremecourt.gov/opinions/15pdf/15-274_p8k0.pdf (29/09/2016). 
la IVE que equiparasen sus estándares quirúrgicos a los exigidos a los centros de cirugía ambulatoria, y a realizar convenios con hospitales situados a menos de 45 kilómetros en los que se previera la posibilidad de internar a las pacientes a la que se hubiera realizado una IVE en caso de que fuera necesario. Debido a la dificultad de cumplir con los nuevos estándares sanitarios, casi la mitad de las clínicas autorizadas para realizar la IVE en Texas tuvieran que cerrar, con lo cual las distancias entre las diferentes poblaciones y los centros que permanecieron abiertos en algunos supuestos se incrementaron considerablemente.

En su análisis del asunto, el tribunal llegó a la conclusión de que la legislación objeto de debate no mejoraba de forma relevante los estándares sanitarios, especialmente porque las estadísticas indicaban que la mayoría de las complicaciones que se producen en este tipo de intervenciones suelen aparecer cuando el paciente abandona la clínica. Asimismo, el tribunal estimó que la normativa obstaculizaba injustificadamente el derecho de las mujeres a la IVE, bien incrementando de forma considerable y sin justificación sanitaria su coste económico (las clínicas tuvieron que incrementar sus precios para cumplir con los nuevos estándares de seguridad sanitaria), bien obligando en numerosos supuestos a las pacientes a desplazarse distancias considerables (al cerrar numerosas clínicas). En palabras del tribunal, «los Estados tienen un interés legítimo en velar porque las IVE se realicen en un contexto que garantice la máxima seguridad posible para la salud de los pacientes [...] ahora bien, las normas aprobadas por los Estados en este terreno pierden la consideración de instrumentos válidos para la consecución de fines legítimos, cuando obstaculizan de forma relevante las decisiones de las mujeres e impiden que éstas puedan ejercer sus derechos ${ }^{96}$.

La garantía del derecho de las mujeres a la IVE fue el elemento central de la decisión del Tribunal Supremo, de forma que, como ha expuesto Lindberg, «rechazando la ley de Texas, la Corte reafirmó enérgicamente su precedente en el sentido de apoyar el derecho al aborto. Y, habiendo confirmado su postura respecto a ese pretendido derecho constitucional, la mayoría de la Corte no parece que esté receptiva en aceptar las objeciones de conciencia que respecto al aborto o anticoncepción se puedan dar» ${ }^{97}$.

En el asunto Burwell v. Hobby Lobby Stores ${ }^{98}$, el Tribunal Supremo se pronunció sobre la constitucionalidad de la parte de la reforma sanitaria impul-

96 Vid. Roe v. Wade, 410 U. S. 113, 15 (1973), y Planned Parenthood of Southeastern Pa. v. Casey, 505 U. S. 833, 877 (1992).

97 Posse-Blanco Lindberg, D., ¿Protección jurídica del derecho a la objeción de conciencia?, cit., p. 12 .

98573 U. S. (2014) El texto completo de la decisión se encuentra en: http://www.supremecourt.gov/opinions/13pdf/13-354_olp1.pdf (29/09/2016). 
sada por la administración Obama que requiere a los empresarios contratar seguros médicos que cubran medidas anticonceptivas para sus empleados; en este contexto, el tribunal tuvo que determinar qué personas jurídicas están protegidas por el RFRA, así como la posibilidad de diferenciar entre éstas atendiendo a sus finalidades y ánimo de lucro.

El supuesto de hecho fue el siguiente. El Department of Health and Human Services (HHS), en ejecución del Patient Protection and Affordable Care Act de 2010 (ACA $)^{99}$, ordenó que los seguros médicos de las empresas con un determinado número de empleados debían proporcionar a sus empleadas cuidados y exámenes médicos preventivos, sin que pudiera exigirse ninguna medida de copago para disfrutar de dichos tratamientos médicos ${ }^{100}$. Las empresas con menos de 50 empleados, las confesiones religiosas y las organizaciones sin ánimo de lucro con fines religiosos fueron exentas de la aplicación de esta norma, en el supuesto de que la cobertura sanitaria aludida colisionase con sus principios o ideario religioso. En esos supuestos excepcionales, la norma establecía que el emisor del seguro debía excluir los métodos anticonceptivos del plan médico contratado por el empleador, y proporcionar dichos métodos de forma gratuita a los empleados.

La regulación federal ordenaba a los empleadores ofrecer a sus empleados cobertura sanitaria para 20 métodos anticonceptivos, entre los que se incluían aquellos que pueden tener el efecto de impedir que un óvulo fecundado se desarrolle o entre en contacto con el útero. Un grupo de empresarios, cuyas creencias religiosas se soportan en la idea de que la vida humana comienza en la concepción, denunciaron la regulación señalada, en el entendimiento de que facilitar a sus empleados el acceso a métodos anticonceptivos o a medicamentos que actuasen contra la concepción es contrario a su libertad religiosa, por lo que solicitaron que, bien se anulase la regulación aludida, bien se reconociese su derecho a la objeción de conciencia. El gobierno justificó la relevancia de la norma en la necesidad de garantizar el acceso de la población a métodos anticonceptivos, pero no pudo demostrar que la obligación impuesta a los empleadores (de que fueran éstos los responsables de proporcionar la cobertura médica) era la medida menos restrictiva que podía imponerse al ejercicio del derecho de libertad religiosa.

Con carácter previo, el tribunal tuvo que determinar qué personas jurídicas están protegidas por el RFRA, así como la posibilidad de diferenciar entre éstas atendiendo a sus finalidades y ánimo de lucro. El tribunal estimó que las entidades con ánimo de lucro estaban protegidas por el RFRA, ya que, en su opinión,

99 El texto de la norma puede encontrarse en http://housedocs.house.gov/energycommerce/ ppacacon.pdf (29/09/2016).

10042 U. S. C. $\$ 300 g g-13(a)(4)$.

(C) UNED. Revista de Derecho Politico 
no tendría sentido eximir a un entidad de la protección de un norma que garantiza el ejercicio de un derecho fundamental exclusivamente atendiendo a su ánimo de lucro, pues, con independencia de la existencia o no del ánimo de lucro, la lesión al derecho fundamental se produciría igualmente ${ }^{101}$.

Respecto al fondo del asunto, el tribunal estableció por una ajustada mayoría de 5 votos contra 4 que la norma federal lesionaba el derecho a la libertad religiosa de los demandantes. El tribunal estimó que el Estado podría haber asumido directamente el coste médico de proporcionar las medidas anticonceptivas a las empleadas, cuando sus empresas no quisieran proporcionarles dichos medios por motivos ideológicos o religiosos. Esta posibilidad se preveía de forma excepcional para los empleados de las organizaciones religiosas o de las organizaciones sin ánimo de lucro con un ideario o una finalidad religiosa. La conversión de la medida excepcional en la regla general beneficiaría a todas las partes implicadas: los empresarios no tendrían que optar entre traicionar sus creencias religiosas o pagar una multa, los empleados podrían acceder a las medidas anticonceptivas con independencia de las creencias de sus empleadores, y el gobierno conseguiría los objetivos que se había planteado con la reforma sanitaria en el terreno de la planificación familiar.

El nexo común de las decisiones del Tribunal Supremo en los asuntos Whole Woman's Health y Hobby Lobby es la configuración de la IVE como un derecho de las mujeres que, si bien carece de naturaleza prestacional, no puede ser limitado como consecuencia del ejercicio del derecho a la objeción de conciencia de un tercero u obstaculizado discrecionalmente por parte de los Estados. El reconocimiento del derecho a la objeción de conciencia en este terreno está supeditado, tal y como expuso el voto mayoritario en el asunto Hobby Lobby, a que, con independencia de quien se haga cargo de la prestación de las medidas anticonceptivas (el empleador, la aseguradora o el gobierno), todas las mujeres puedan acceder a las mismas en igualdad de condiciones, de forma que el reconocimiento del derecho a la objeción de conciencia no genere un perjuicio en el derecho de un tercero o le discrimine en su ejercicio.

El Tribunal supremo ha tenido la posibilidad de pronunciarse de nuevo sobre esta temática con ocasión del asunto Zubik v Burwell ${ }^{102}$. Como hemos señalado anteriormente, el ACA exime a las organizaciones sin ánimo de lucro con fines religiosos de su ámbito de aplicación, ordenando que el emisor de seguro exclu-

101 En palabras de Alito, que redactó el voto mayoritario, «no conceivable definition of the term includes natural persons and nonprofit corporations, but not for-profit corporations».

102 136 S. Ct 1557 (2016) 578 U. S. ___ (2016). El texto completo de la decisión se encuentra en: https://www.supremecourt.gov/opinions/15pdf/14-1418_8758.pdf (29/09/2016). 
ya los métodos anticonceptivos del plan médico contratado por el empleador, y proporcione dichos métodos de forma gratuita a los empleados de las organizaciones mencionadas.

Las organizaciones sin ánimo de lucro con fines religiosos debían presentar un formulario notificando al gobierno que se oponían por motivos de conciencia a proporcionar a sus empleados un seguro médico, que incluyese métodos anticonceptivos; a continuación, la administración ordenaba a las aseguradoras que proporcionasen la cobertura relacionada con los métodos anticonceptivos a los empleados de las organizaciones objetoras sin que éstas asumieran su coste económico. Las Hermanitas de los pobres, que gestionaban más de 25 hogares para ancianos con bajos ingresos, objetaron en conciencia a presentar el formulario de exención a la administración, en el entendimiento de que la presentación de la solicitud de exención suponía que el sistema les convertía en cooperadores necesarios en la prestación de servicios médicos contrarios a sus principios religiosos. Otras organizaciones sin ánimo de lucro con fines religiosos presentaron objeciones similares al cumplimiento del ACA.

Durante el proceso, las organizaciones demandantes alegaron que sus creencias religiosas no serían violentadas en el supuesto de que pudieran contratar un seguro médico que no incluyese medidas anticonceptivas, con independencia de que las autoridades federales de oficio ofertasen esa cobertura, pero siempre que las organizaciones no tuvieran que participar en el proceso para que sus empleados accediesen a las medidas anticonceptivas. Finalmente, el tribunal no se pronunció sobre el fondo del asunto, y remitió los casos a los tribunales de apelación respectivos para que las partes tuvieran la oportunidad de llegar a un acuerdo que permita, por una parte, que las mujeres, con independencia de quien sea su empleador, puedan disfrutar de seguros médicos que incluyan cobertura anticonceptiva; y por la otra, que dicha medida sea compatible con las demandas de las organizaciones religiosas demandantes ${ }^{103}$.

\subsection{La objeción de conciencia farmacéutica}

Los Estados han regulado de forma dispar la posibilidad de que los farmacéuticos puedan objetar en conciencia a dispensar medicamentos que atenten contra sus creencias o convicciones personales. Según Palomino, es posible dife-

103 La peculiar decisión del tribunal ha sido justificada en el hecho de que los jueces estuviesen divididos en 2 posiciones claramente contradictorias defendidas cada una de ellas por 4 jueces, debido a que en ese momento no estaba cubierta la vacante del Juez Scalia. Vid. IsAacson, S. E., (2016). Derechos Establecidos y Nuevos Desafíos, cit., p. 17. 
renciar 3 modelos diferentes en este contexto: por una parte, un grupo de Estados protege la objeción de conciencia del farmacéutico de forma específica; por otra, otros Estados, de forma complementaria al reconocimiento de la objeción de conciencia del farmacéutico, han promulgado legislación conducente a evitar la discriminación de los farmacéuticos en función de sus concretas creencias o convicciones; y por último, la legislación de algunos Estados prohíbe a los farmacéuticos el ejercicio de la objeción de conciencia ${ }^{104}$.

El Tribunal Supremo federal no se ha pronunciado expresamente sobre la posibilidad de que los profesionales farmacéuticos puedan objetar a dispensar medicamentos por motivos de conciencia, más allá que para negarse, el 28 de junio de 2016, a pronunciarse sobre el recurso presentado contra una decisión del Tribunal de Apelaciones del noveno circuito sobre este particular ${ }^{105}$. En este sentido conviene tener presente que el Tribunal Supremo decide discrecionalmente sobre la admisión de los asuntos, y esta posibilidad está supeditada a que al menos cuatro de los nueve jueces que integran el tribunal estimen que el asunto que se presenta tiene interés o relevancia constitucional ${ }^{106}$.

El supuesto de hecho fue el siguiente. Los miembros de la familia Stormans poseían y gestionaban un establecimiento que combinaba las funciones de supermercado y farmacia en Olympia, en el Estado de Washington. Los Stormans tienen profundas creencias religiosas cristianas, y entienden que el uso de métodos artificiales conducentes a prevenir la implantación en el útero de un óvulo fertilizado es equivalente al aborto, que es una práctica contraria a sus creencias. Para evitar contradecir sus creencias religiosas, la farmacia regentada por los Stormans ni almacenaba ni dispensaba contraceptivos de emergencia, como, por ejemplo, la PDD. Cuando un usuario solicitaba que le fuera dispensado un contraceptivo de emergencia, presentando la receta firmada por un facultativo habilitado a tales efectos, los empleados de la farmacia informaban de que por motivos de conciencia carecían de ese tipo de medicamentos, e indicaban a sus usuarios cuál era la farmacia más próxima en la que podían obtener el contraceptivo. En un radio de 5 millas del establecimiento de los Stormans era factible obtener medicación contraceptiva en aproximadamente 30 establecimientos, sin que ningún usuario de la farmacia hubiese presentado ninguna queja a este respecto.

104 Palomino Lozano, R., (2007). Nuevos supuestos y formas de objeción de conciencia, cit., p.17.

105 Stormans, Inc. v. Wiesman 579 U. S. (2016).

106 Vid. Hualde López, I. (2015). «Una aproximación al Tribunal Supremo y certiorari norteamericano», Cuadernos de derecho transnacional, Vol. 7, N. ${ }^{\circ}$ 1, pp. 71-95. 
En el 2007 la Junta farmacéutica del Estado de Washington aprobó dos normas que modificaron el marco descrito. La primera norma ordenó a las farmacias dispensar los medicamentos y/o dispositivos legamente prescritos a sus pacientes. La segunda norma estableció que las farmacias debían almacenar determinadas cantidades de medicamentos para atender a las necesidades farmacéuticas de sus clientes, incluyéndose en este listado los denominados contraceptivos de emergencia ${ }^{107}$. Hasta la reforma del 2007 las farmacias no estaban obligadas a almacenar contraceptivos de emergencia, y en consecuencia sus titulares podían remitir legalmente a sus pacientes a otras farmacias al carecer de existencias; pero en virtud de la nueva normativa las farmacias fueron obligadas tanto a almacenar como a dispensar contraceptivos de emergencia.

La legislación descrita preveía supuestos excepcionales en los cuales las farmacias podían negarse a dispensar medicamentos, como, por ejemplo, cuando la prescripción fuera errónea o contradictoria, en caso de emergencia nacional o estatal, cuando la prescripción pareciera fraudulenta o el paciente se negase a pagar el medicamento, o en el caso de equipamientos o recetas médicas que requirieran conocimientos médicos muy elevados y/o especializados para su preparación.

Rall Stormans y dos farmacéuticos más denunciaron que la normativa del 2007 lesionaba su derecho a la libertad religiosa y que no era ideológica y/o religiosamente neutral. Según los demandantes, la normativa aprobada por la Junta farmacéutica permitía a los farmacéuticos no dispensar medicamentos por motivos de naturaleza secular, pero no se preveía la posibilidad de objetar a dispensar medicamentos por motivos estrictamente religiosos. La normativa permitía negar el acceso a los medicamentos a los pacientes en determinados supuestos, e incluso aunque estuvieran correctamente recetados, por lo que su finalidad no era garantizar el acceso de los pacientes a las medicaciones que les fueran prescritas ${ }^{108}$.

En primera instancia, un Tribunal de Distrito estimó que las disposiciones mencionadas eran contrarias a la establishment clause, al entender que el principal objetivo de la reforma del 2007 fue evitar que los farmacéuticos pudieran negar-

107 Vid. Wash. Admin. Code \$246-869-010(1), y 246-869-150(1) (2009).

108 Los demandantes citaron el precedente Church of the Lukumi Babalu Aye, Inc. v. Hialeah, 508 U. S. 520 (1993), donde el Tribunal Supremo señaló que la legislación estatal cuyo principal objeto fuera fomentar o impedir el ejercicio de la libertad religiosa era contraria a la establishment clause. 
se a dispensar medicamentos contraceptivos o anticonceptivos de emergencia alegando motivos religiosos o morales ${ }^{109}$.

El Tribunal de Apelaciones anuló la sentencia de instancia, al entender que la normativa aprobada por la Junta farmacéutica del Estado de Washington era ideológica y religiosamente neutral. En opinión del tribunal, la normativa enjuiciada, por una parte, pretendía evitar que las creencias o convicciones de los farmacéuticos o sus empleados impidiesen a los pacientes ejercer su derecho a acceder a la medicación que les fuera prescrita; por otra, garantizó que el acceso a los contraceptivos de emergencia se realizase de forma rápida y efectiva, especialmente en las áreas rurales donde hay menos farmacias y su localización geográfica es muy diversa, ya que el tiempo reduce la eficacia de este tipo de medicamentos; y por último, la posibilidad de que un farmacéutico objetase a dispensar contraceptivos de emergencia, remitiendo a la mujer afectada a otra farmacia, podía crear un sentimiento de culpa o de incomodidad que se tradujese en que finalmente la paciente renunciase a su legítimo derecho a acceder a la medicación ${ }^{110}$.

La obligación de los farmacéuticos de almacenar y dispensar medicamentos no se refería exclusivamente a productos contraconceptivos, sino a cualquier medicamento que tuviera que dispensarse previa prescripción médica, entre los que se encuentran los contraceptivos de emergencia. El tribunal estimó que la normativa permitía a los farmacéuticos negarse a dispensar medicamentos tanto por motivos seculares como religiosos, con la diferencia de que en el segundo supuesto la farmacia debía tener en su plantilla a un dependiente que sustituyera al personal que objetara por motivos religiosos. En palabras del tribunal, «la neutralidad no se lesiona por la suposición de que las farmacias cuyos dueños planteen objeciones de conciencia a los contraceptivos de emergencia puedan sufrir una carga desproporcionada, o por la especulación de que los farmacéuticos que objeten en conciencia a dispensar contraceptivos de emergencia tengan que reestructurar las plantillas de sus establecimientos» ${ }^{111}$.

Respecto a los supuestos excepcionales que permitían a las farmacias no dispensar medicamentos, el tribunal estimó que no se trataba de supuestos de naturaleza secular sino de supuestos objetivos que eran operativos con independencia de cuáles fueran las creencias o convicciones del farmacéutico, en los cuales la entrega de un medicamento, bien podía poner en peligro la salud del

109 Vid. Stormans, Inc. v. Selecky, 854 F. Supp. 2d 925, 934 (WD Wash. 2012). El texto completo de la sentencia puede encontrarse en http://cdn.ca9.uscourts.gov/datastore/opinions/2015/07/23/12-35221.pdf (29/09/2016).

110 P. 24.

111 P. 43. 
paciente (dada la incoherencia, atipicidad o complejidad de la prescripción), bien la supervivencia económica de la farmacia (fruto del impago o el fraude).

Por último, el tribunal se pronunció acerca de la relación entre la objeción de conciencia a la IVE y a despachar contraceptivos de emergencia, señalando que «pese a que se asumiese que existe una tradición jurídica que protege a los individuos de su participación obligatoria en actividades que de forma indubitada puedan generar la muerte a un tercero, eso no significa que exista el mismo consenso social en proteger el derecho de los individuos a participar en todas aquellas actividades que en su opinión puedan generar la muerte de un tercero» ${ }^{112}$.

El Tribunal Supremo desestimó el recurso presentado contra la decisión del Tribunal de Apelaciones, y en consecuencia ratificó la sentencia de apelación. La decisión del Tribunal Supremo no fue unánime, destacando, y especialmente por su extensión, el voto particular redactado por el juez Alito, que fue suscrito por los jueces Thomas y Robert, disintiendo con la decisión de la mayoría de negarse a pronunciarse sobre el recurso ${ }^{113}$. La discrepancia de los jueces referidos reside principalmente en su entendimiento de que la normativa aprobada por el Estado de Washington, que prohibía a los farmacéuticos derivar a sus clientes a otros establecimientos por motivos de conciencia, no sirve a un «propósito legítimo» y lesiona el derecho a la libertad religiosa ${ }^{114}$.

Para el voto minoritario, las disposiciones aprobadas por la Junta farmacéutica no eran ideológicamente neutrales, pues permitían «no dispensar medicamentos a personas enfermas que no pudieran pagar su importe [...] por lo que la regulación no prohíbe conductas de naturaleza no religiosa que pueden poner en peligro el interés del Estado en asegurar que todos los pacientes puedan acceder a sus medicaciones, mientras que en el caso de las conductas soportadas en las creencias o convicciones religiosas la norma es inflexible» ${ }^{115}$.

El voto particular también manifestó su preocupación por el hecho de que numerosas farmacias, como ocurría en el caso de los demandantes, tuvieran que cerrar para evitar traicionar las creencias y convicciones religiosas de sus titulares. Esto podría suponer que la normativa objeto de debate lejos de conseguir su objetivo (mejorar el acceso de la población a los medicamentos) obstaculizase el

112 Vid. P. 13 del voto particular.

113 El texto completo del voto particular redactado por el juez Alito puede encontrarse en https://www.supremecourt.gov/opinions/15pdf/15-862_2c8f.pdf (29/09/2016).

114 Para este sector de los jueces esta situación contradecía su jurisprudencia establecida en los asuntos Employment Division v. Smith 494 U. S. 872 (1990), y Church of the Lukumi Babalu Aye, Inc. v. City of Hialeah 508 U. S. 520 (1993).

115 Vid. P. 13 del voto particular.

(C) UNED. Revista de Derecho Politico 
derecho de los pacientes a acceder a los medicamentos. En palabras del voto particular, «la conclusión es clara: Washington prefiere no tener ninguna farmacia a tener una que se niegue a dispensar contraceptivos de emergencia por motivos religiosos, lo cual supone una clara lesión al derecho de libertad religiosa de los demandantes» ${ }^{116}$.

La decisión del Tribunal Supremo en el asunto Stormans ha sido criticada por un sector de la doctrina, en la medida en la que obliga a los farmacéuticos a elegir entre traicionar sus creencias o convicciones personales o no ejercer la profesión farmacéutica ${ }^{117}$. Asimismo, Lindberg ha señalado que con esta decisión el tribunal ha permitido que se discrimine a los objetores en función de que su ideología personal sea de carácter religioso o secular ${ }^{118}$.

La negativa por parte de la mayoría de los jueces del Tribunal Supremo a revisar la decisión del Tribunal de Apelaciones supone que la objeción de conciencia de los farmacéuticos carece de fundamento jurídico en el ordenamiento jurídico estadounidense. Ahora bien, no cabe hablar de unanimidad a este respecto. El sector mayoritario de los jueces interpreta, en la línea del Tribunal de Apelaciones, que el derecho de acceso a la medicación prescrita por los profesionales del sistema sanitario debe primar sobre las creencias y/o convicciones de los farmacéuticos. Por su parte, el sector minoritario de los jueces del Tribunal Supremo entiende que es factible armonizar los derechos de los pacientes y los farmacéuticos, y que en todo caso es preferible disponer de farmacias que no dispensen determinados medicamentos atendiendo a las creencias y convicciones de sus titulares, que carecer de las mismas.

El problema de fondo reside en la dificultad de encontrar un marco regulatorio general que satisfaga los intereses de todas las partes implicadas sin poner en peligro el derecho a la salud. Este proceso se complica ante la posibilidad de permitir la objeción de conciencia en un contexto tan peculiar como es el farmacéutico pues: por una parte, los farmacéuticos prestan un servicio público pero no por ello dejan de ser titulares de derechos y libertades fundamentales; pero, por la otra, el reconocimiento del derecho a la objeción de conciencia en este terreno supone subordinar el acceso a un servicio público fundamental y el ejercicio del derecho a la salud a las creencias y convicciones ideológicas o religiosas de un tercero.

116 Vid. P. 13 del voto particular.

117 Isaacson, S. E., (2016). Derechos Establecidos y Nuevos Desafíos, cit., p. 9.

118 Posse-Blanco Lindberg, D., ¿Protección jurídica del derecho a la objeción de conciencia?, cit. p. 11. 


\section{CONSIDERACIONES FINALES}

El Tribunal Constitucional ha reconocido el derecho a la objeción de conciencia de los farmacéuticos a dispensar la PDD. Se trata de una decisión compleja, que está llamada a tener notable relevancia en la medida en la que el tribunal interpreta que la objeción de conciencia puede ser ejercida, con independencia de que exista una regulación previa por parte del legislador que habilite su ejercicio. La principal cuestión que deja abierta la decisión del Tribunal Constitucional es: ¿cómo armonizar el ejercicio de la objeción de conciencia con los derechos de los usuarios con la correcta prestación del servicio público farmacéutico? La cuestión no es baladí, pues la decisión del tribunal habilita que los farmacéuticos puedan objetar masivamente a dispensar la PDD, y no parece lógico hacer depender el ejercicio de los derechos en juego a la concreta ubicación geográfica de los usuarios del servicio público o a las creencias o convicciones específicas de los farmacéuticos.

Desde la perspectiva de la necesidad de interpositio legislatoris para ejercer la objeción de conciencia es factible realizar dos lecturas de la decisión del tribunal, pero en ambos supuestos de difícil encaje en nuestro sistema jurídico. Podría interpretarse que los estatutos y los códigos deontológicos aprobados por los colegios profesionales serían las disposiciones normativas que habilitan el ejercicio de la objeción. Esta opción presenta la ventaja de que no supone una ruptura con la doctrina constitucional que venía requiriendo la interpositio legislatoris, pero jurídicamente no es viable pues propone convertir a un derecho estatutario en fuente de derecho oponible a normas imperativas, que en algunos casos tienen rango constitucional. La segunda opción sería interpretar que la objeción de conciencia no requiere la interpositio legislatoris, y que los tribunales deben reconocer caso por caso los supuestos de objeción de conciencia; esta opción, si bien es habitual en los modelos jurídicos de common law, presenta numerosos inconvenientes, entre los que destacan: la ausencia de seguridad jurídica, el desafío que este modelo supondría para nuestro Estado de derecho, y la articulación del papel de los jueces con su sometimiento al imperio de la ley (117.1. CE).

El debate sobre las consecuencias jurídicas de la negativa de los farmacéuticos a dispensar medicamentos por motivos de conciencia no ha sido exclusivo de nuestro país. Como hemos visto, los tribunales franceses, estadounidenses y el TEDH se han pronunciado sobre el mismo supuesto que se ha planteado ante nuestro Tribunal Constitucional, estableciendo que las creencias y convicciones personales de aquellas personas que son garantes del ejercicio de derechos como la salud o la integridad física y psíquica no pueden primar sobre los derechos de sus usuarios y pacientes. Los argumentos esgrimidos por los tribunales referidos 
son numerosos, y entre ellos destaca la incongruencia resultante de que un modelo sanitario confíe el monopolio del servicio público de dispensación de medicamentos a un colectivo, y que a continuación éste pueda negarse a ejercer su función alegando una lesión a su derecho a la libertad de conciencia, con el consecuente perjuicio que se genera con carácter general a la prestación de un servicio público, y de forma específica a los derechos y libertades de terceros.

La configuración de la objeción de conciencia farmacéutica operada por el Tribunal Constitucional no es coherente con la jurisprudencia del TEDH, pues el tribunal de Estrasburgo ha señalado que tanto la objeción de conciencia con carácter general, como el supuesto específico de la negativa de los farmacéuticos a dispensar medicamentos por motivos de conciencia, no forman parte del derecho a la libertad de pensamiento, conciencia y religión, garantizado en el artículo 9 CEDH. La objeción de conciencia al cumplimiento del servicio militar es la única excepción amparada por el tribunal, debido a la dificultad de prohibir esta práctica en el marco de una sociedad democrática y a que existe unanimidad de los países europeos en este sentido.

La receta que ofrece la jurisdicción federal estadounidense coloca en el centro del debate la posibilidad de que el usuario del servicio farmacéutico pueda ejercer sus derechos sin ser discriminado en función de las creencias o convicciones de su farmacéutico. Los farmacéuticos son libres para tener las creencias o convicciones que deseen, y para asegurar que su ejercicio no tenga consecuencias en la prestación de un servicio público éstos deben prever la posibilidad de que haya empleados dispuestos a dispensar los medicamentos que les soliciten. El ejercicio de la objeción de conciencia está condicionado por su colisión contra un elenco de derechos centrales para el libre desarrollo de la personalidad de los pacientes; sin embargo, en este caso concreto, dado que el ordenamiento jurídico no reconoce el derecho a la objeción de conciencia farmacéutica, no cabe hablar de un conflicto de derechos.

El conflicto entre norma y conciencia ha sido resuelto por la judicatura estadounidense intentando no sacrificar la relevancia de los bienes jurídicos en juego (objeción de conciencia versus libre desarrollo de la personalidad en el terreno de la salud y la sexualidad); ahora bien, dada la atipicidad de este supuesto, así como la imposibilidad de articular mecanismos objetivos que garanticen la correcta prestación del servicio público, el tribunal se ha decantado por un modelo en el cual las farmacias tienen la obligación de dispensar la medicación que legalmente les requieran sus pacientes, organizando sus plantillas de forma que no se obligue a ningún individuo a dispensar medidas anticonceptivas de emergencia contra su conciencia (puede hacerlo otro empleado o titular del negocio). 
En resumen, el Tribunal Constitucional ha dado el paso de reconocer a los farmacéuticos el derecho a no dispensar la PDD por motivos de conciencia, con una decisión que está llamada a tener especial relevancia en la futura conformación de la objeción de conciencia en nuestro ordenamiento jurídico, y que relega a un segundo plano los derechos de las mujeres en este terreno. Con esta decisión nos alejamos de las soluciones que han adoptado otros países de nuestro entorno jurídico que han sido avaladas por el TEDH, y se ignoran las valiosas lecciones del modelo estadounidense, que cuenta con una dilatada experiencia legislativa y jurisprudencial en el terreno de los conflictos entre norma y conciencia.

Title:

Pharmacists' Right to Conscientious Objection. A Comparative analysis of Spanish and US models.

\section{Summary:}

1. Introduction. 2. Conscientious objection. 2.1 Content and limits. 2.2 Legal nature. 2.3 Pharmacists' Right of Conscientious Objection. 2.3.1 Courts decisions overview. 2.3.2 Constitutional Court decisions. 3. European Court of Human Rights decisions. 4. Conscientious objection in the US legal system. 4.1 Constitutional framework. 4.2 Conscientious objection in the health care system. 4.3 Pharmacists' Right of Conscientious Objection. 5. Final considerations.

\section{Resumen:}

El objeto de este estudio es analizar la objeción de conciencia farmacéutica tanto en nuestra reciente doctrina constitucional como en la jurisprudencia del Tribunal Supremo federal estadounidense y del Tribunal Europeo de Derechos Humanos, para intentar explicar la coherencia (o incoherencia) de nuestro modelo de objeción de conciencia farmacéutica con el marco constitucional, así como en qué medida la posición de nuestro Tribunal Constitucional se asemeja a la de los tribunales referidos.

La elección del modelo estadounidense se debe a que este ordenamiento jurídico tiene una dilatada experiencia en la regulación y resolución de conflictos relacionados con la objeción de conciencia; y en el caso 
concreto de la objeción de conciencia farmacéutica el Tribunal Supremo federal acaba de pronunciarse sobre un supuesto planteado en términos muy similares al resuelto en la STC 145/2015, aunque utilizando una receta muy diferente a la nuestra para resolver el conflicto entre norma y conciencia.

La primera parte del artículo analiza la naturaleza jurídica de la objeción de conciencia en nuestro ordenamiento jurídico, así como las decisiones de nuestro Tribunal Constitucional en este terreno. Esto nos permitirá conocer cuál es la relación entre la libertad de conciencia y la objeción de conciencia, así como en qué medida es necesario que el legislador reconozca expresamente la posibilidad de que los individuos no cumplan con aquello que señala el ordenamiento jurídico por motivos de conciencia, para hablar de un hipotético derecho a la objeción de conciencia.

La segunda parte se dedica al análisis del modelo constitucional estadounidense, y al estudio de las decisiones del Tribunal Supremo federal en el terreno de la objeción de conciencia en el contexto sanitario, incluyéndose en este apartado su posición sobre la objeción de conciencia del personal farmacéutico.

El artículo concluye ofreciendo una serie de reflexiones acerca de las diferentes respuestas que los modelos estudiados proponen, y su respectivo encaje constitucional. En este sentido, hay que destacar que nuestro Tribunal Constitucional ha dado el peligroso paso de reconocer a los farmacéuticos el derecho a no dispensar la píldora del día después por motivos de conciencia, con una decisión que está llamada a tener especial relevancia en la futura conformación de la objeción de conciencia en nuestro ordenamiento jurídico. Con esta decisión nos alejamos de las soluciones que han adoptado otros países de nuestro entorno jurídico, y que habían sido avaladas por el TEDH; asimismo, se ignoran las valiosas lecciones del modelo estadounidense, el cual ha intentado no sacrificar y armonizar los bienes jurídicos en juego, articulando mecanismos que garantizan la correcta prestación del servicio público.

\section{Abstract:}

This paper analyzes the responses of the Spanish legal system, in contrast to the jurisprudence of the US Federal Supreme Court and the European Court of Human Rights, to a refusal by pharmacists to dispense drugs for reasons of conscience. In this context are studied: the Spanish jurisprudence and constitutional doctrine, the jurisprudence of the European Court of Human Rights, and the most important decisions of the US federal Courts. It attempts to explain the consist- 
ency (or inconsistency) of our model of pharmaceutical conscientious objection to the constitutional framework, and to what extent the position of our Constitutional Court resembles that of the courts utilized for comparison.

The choice of the American model is due to this legal system's extensive experience in the regulation and resolution of conflicts related to conscientious objection. Indeed, in the specific case of pharmaceutical conscientious objection, the Federal Supreme Court recently ruled on a case based on issues very similar to those determined in the STC $145 / 2015$ case, although utilizing a very different methodology from ours in order to resolve the conflict between norm and conscience.

The first part of the article analyses the legal nature of conscientious objection in our legal system, and the decisions of our Constitutional Court in this field. This permits us to understand the relationship between freedom of conscience and conscientious objection, and to what extent it is necessary that legislators expressly recognize the possibility that individuals will not comply with the law on grounds of conscience, so that we may speak of a hypothetical right to conscientious objection.

The second part of the article is devoted to the analysis of the American constitutional model in the field of freedom of conscience, and especially the study of the decisions by the Federal Supreme Court on the grounds of conscientious objection in the context of health. Included in this section are its positions on conscientious objection by pharmaceutical staff.

The article concludes by offering a series of reflections on the different responses suggested by the models studied, and their respective constitutional relevance. In this regard, it is noteworthy that our Constitutional Court has taken the dangerous step of recognizing the right of pharmacists to refuse to dispense the morning-after pill for reasons of conscience, a decision that will be called to play a particularly important role in shaping the future of conscientious objection in our legal system, and which relegates to the rights of women in this field to a secondary status. With this decision we move away from the solutions that other countries in our legal environment have adopted, and that furthermore had been endorsed by the ECHR. Similarly, our legal system ignore the valuable lessons of the American model, which has attempted to not sacrifice -but rather to harmonize- the legal interests at stake, thus articulating mechanisms that ensure the proper provision of public service. 
Palabras clave:

Objeción de conciencia, libertad de conciencia, Derecho comparado, derechos de los farmacéuticos, deber legal de dispensar medicamentos.

Keywords:

Conscientious objection, freedom of conscience, pharmacists' rights, comparative law, legal obligation to dispense medications. 